\title{
La Antropología y el estudio de la Geografía
}

\author{
Leif Korsbaek \\ lkorsbaek@yahoo.com.mx \\ Instituto Nacional de Antropología e Historia. México
}

\section{Introducción}

Así como la Antropología mantiene vínculos con la disciplina más especulativa de todas, la Filosofía, también mantiene relaciones con una de las disciplinas más terrenales, con la Geografía, ciencia de la Tierra. A un nivel elemental, podemos decir que un antropólogo que se dirige al campo sin buscar la información básica acerca de la colocación de su comunidad o región, los tipos de suelos, vegetación, orografía, etc., está literalmente "perdido en el espacio".

Cualquiera que dude de la íntima relación entre las diferentes ciencias naturales y sociales en general, y entre la antropología y la geografía en particular, se puede convencer fácilmente, echando un vistazo a la carrera de Franz Boas: empezó como científico natural, escribiendo su tesis doctoral acerca de la polarización de la luz a través del agua marina, luego cambió sus intereses hacia la geografía y, finalmente, tendió un puente entre la geografía cultural y la antropología, para dedicarse por completo a esta última disciplina (Rutsch, 1984: 75-78).

Se advierte fácilmente que la geografía comparte uno de sus vicios con la antropología: es una disciplina muy nacionalizada, en el sentido de que de la misma manera que es imposible no darse cuenta de las diferencias que separan una antropología social británica de una antropología cultural norteamericana, y ambas de una etnología más especulativa francesa, así también es inmediatamente visible en la geografía una tradición alemana, otra francesa, otra británica y otra estadounidense, y se puede plantear también una tradición geográfica específicamente mexicana.

Tanto la geografía como la antropología son disciplinas jóvenes. En 1887 escribió Franz Boas, en aquel entonces todavía trabajando como geógrafo, que "casi cada geógrafo distinguido ha sentido la necesidad de expresar sus opiniones acerca de sus metas y objetivos, y defenderla contra ser absorbida por la geología, la botánica, la historia y otras ciencias que tratan problemas similares o idénticos a los de la geografía; si los representantes de una ciencia tan joven como es la geografía gastan una buena parte de su tiempo en discusiones de ese tipo" (Boas, 1887: 639), entonces, concluye Boas, se debe a una profunda diferencia entre la apreciación de los científicos geógrafos y sus adversarios. Unos cuarenta años más tarde escribió Alfred Louis Kroeber, curiosamente en un artículo acerca de su profesor Franz Boas, casi lo mismo acerca de la antropología: "en el mero 
hecho de que las escuelas antropológicas abogan cada una por su programa hay algo de inmaduro, partisano o inacabado" (Kroeber, 1935: 540).

Igual que la antropología es difícil de encasillar en una definición clara y concisa que establezca una nítida frontera que la separe de las demás disciplinas, también "la geografía es una ciencia difícil de definir, porque es a la vez ciencia natural y ciencia social" (Cortez, comp., 1991: 9) y, podríamos agregar, ciencia cultural. Así que es lógico que la geografía también se divide en un gran número de especialidades o subdisciplinas: geografía social, geografía cultural, geografía humana, geografía política, geografía económica, pero esta multitud de especialidades se agrupan en dos grandes aglomeraciones: la geografía humana y la geografía física.

En el presente artículo se persigue el desarrollo histórico de la geografía y los puntos en los cuales ha sido posible un contacto entre la antropología y la geografía, o acaso ha sido inevitable tal contacto, teniendo en mente que no estamos comparando en diferentes momentos disciplinas diversas y claramente perfiladas y definidas, sino procesos de formación disciplinaria e interdisciplinaria que en distintos momentos se conjugan de maneras muy dispares.

La parte final del artículo, probablemente la parte más emocionante, es una búsqueda de huellas geográficas en varias tendencias de la antropología actual para terminar en una serie de propuestas: líneas de investigación y análisis de la zona de colindancia donde ya se ha hecho el trabajo inicial y donde quedan tareas por cumplir.

Una posición que ejemplifica los puntos de vista que hacen indispensable alguna comunicación entre la antropología y la geografía es que "el espacio no es nada sin sus creadores, que son a la vez sus usuarios. Los productores del espacio no son sino los actores sociales, que son tanto productores como consumidores; al mismo tiempo autores, actores y espectadores" (Hoffman \& Salmerón, coord., 1997: 22). Ni es la geografía exclusivamente el estudio del espacio y del terreno, sin tomar en cuenta factores no materiales que "habitan" el espacio y el terreno, ni es la antropología un estudio de la cultura, la estructura social y la evolución, sin tomar en cuenta el espacio y el terreno donde se llevan a cabo estos procesos.

\section{La geografía como disciplina}

Si aceptamos que la esencia de cualquier geografía con una inclinación hacia el campo de la antropología es la importancia del ambiente sobre la sociedad podemos ya buscar un planteamiento muy temprano en el tratado De los aires, aguas y lugares de Hipócrates, donde hace una distinción entre las gentes de las tierras altas, húmedas y batidas, y donde plantea que "por la influencia de los vientos, las gentes son de elevada estatura y de condición, a la vez dulce y bravía, y los habitantes de las tierras ligeras, descubiertas sin agua, de variaciones climáticas bruscas son nervios, secos, más bien rubios que morenos y de carácter arrogante e indócil" (Wartofsky, 1986: 114).

Platón ofrece en el Libro $\mathrm{V}$ de Las leyes más o menos la misma argumentación, según la cual la condición ambiental donde vive el hombre marcará su carácter y su sociedad, igual que Aristóteles, en los Libros IV y VII de la Política. Quedándonos en el mundo clásico europeo, Lucrecio, en el Libro VI de De natura rerum mantiene aproximadamente la misma posición, siguiendo a Galeno y Polibio que la comparten, solamente con pequeñas variaciones (Moreno, 1975).

Uno de los problemas "prácticos" en la Edad Media fue combinar el calendario solar juliano, que determinaba las actividades cotidianas y su planeación, con el calendario hebreo lunar, que determinaba los eventos religiosos relacionados con la Pascua, y solamente 
en el siglo IV se logró, después de interminables pleitos en numerosos concilios, fijar un periodo de 19 años que, con cierta aproximación, permite una coincidencia entre los dos calendarios. Aquí entra en el escenario Beda, un monje británico con tendencias a un pensamiento científico: "La principal contribución de Beda, expuesta en varios tratados, comenzando con el De Temporibus, escrito en el 703 para sus alumnos en Jarrow, fue poner en orden todo esto problema" y "su descripción de las mareas en el De Temporum Ratione (capítulo 29), acabado en el 725 y el más importante de sus escritos científicos, no sólo muestra la curiosidad práctica que compartía con sus compatriotas de Northumbria, sino que también contiene los elementos básicos de la ciencia de la naturaleza", y en el que "enunció por vez primera el principio que conocemos como el establecimiento de un puerto. Este afirma que las mareas retardan respecto a la Luna intervalos definidos que pueden diferir en puntos distintos de la misma costa, de tal forma que las mareas han de ser tabuladas por separado en cada puerto" (Crombie, 1989: 34-35). La lógica es interesante: una civilización, como en este ejemplo la civilización medieval en Europa, define en su cultura lo que es importante y dedica sus recursos humanos y materiales a estos asuntos, dejando un tanto al lado los asuntos definidos como menos importantes; según esta lógica se invirtieron notables recursos en el estudio del calendario con el fin de poder fijar la pascua, y como producto secundario surge un estudio teórico que puede servir para la construcción de puertos y para su manejo. Será un interesante experimento sugerirle al CONACYT que invirtieran los recursos de la República Mexicana en investigaciones dirigidas hacia las necesidades religiosas, limitando la atención a la construcción de puertos en la Costa Pacífica y en el Golfo a los conocimientos secundarios que se producirán en este contexto.

Más tarde, en el siglo XVII, el Abate Dubos, heredero de la tradición griega, enfrenta un problema a la vez más restringido y desmesuradamente más complicado y sutil: el de las condiciones físicas del progreso literario y artístico. Estudiando "el poder del viento sobre el cuerpo humano", como prueba del carácter de las naciones, e incluso pasa revista a los climas que son más propicios que otros a las ciencias y las artes.

Pero la ciencia moderna de geografía nace a partir de la Ilustración del siglo XVIII: "Ritter, junto con Alexander von Humboldt, sigue siendo considerado como uno de los fundadores de la geografía científica moderna" y "la vida de Ritter abarcó la Ilustración alemana, el Romanticismo, y -más claramente aún que el caso de Humboldt-su obra reflejó su participación activa en todos los movimientos intelectuales de su tiempo" (Plewe, 1969: 381).

Acerca de Humboldt, nadie duda de su importancia como pensador geográfico muy político, con la posible excepción de Ortega y Medina que, a pesar de que habla de "esta figura notable en la que se conjugan una formación científica y politécnica bastante amplia", opina también acerca de la misma formación que "es poco profunda", y acerca de Humboldt que "sus dotes y habilidades literarias son muestras vanidosas", lo hizo "no con objeto ciertamente de profundizarlos o investigarlos a conciencia, sino sólo atraído por una insaciable y, las más de las veces, inmodesta curiosidad" y que "tenía una manifiesta inhabilidad para analizar y verificar los datos, pero sobre todo su falla extrema fue su incapacidad para insistir y profundizar sobre un tema o fenómeno hasta alcanzar sus raíces", y lo abandonaría "una vez que satisfizo su tornadizo gulusmeo" (Ortega, 1965: IX-XII).

Es notable la contribución de Humboldt al desarrollo de la geología; al principio del siglo XIX "no se sabía si en toda la superficie del planeta se podrían encontrar rocas de una sola y misma calidad, y si éstas se presentarían en el mismo orden de capas sedimentarias. Fue durante su estancia en América que Humboldt obtuvo una clara idea de la estructura geológica de América del Sur. A partir de esta adquisición, Humboldt escribió por 1823 el 
trabajo intitulado Essai géognostique sur le gisement des roches dans les deux hémispheres. En esta obra, Humboldt demuestra que la estructura de la corteza terrestre es idéntica en los dos hemisferios y que está formada, con pocas diferencias, por rocas de una sola y misma calidad que, en conjunto, forman las mismas capas sedimentarias" (expresó D. I. Cherbakov en Berlín en 1959, citado por Labastida, 1981: 77, nota 5). Pero para la mayoría, Humboldt es geógrafo.

La contribución a la geografía que hizo Humboldt puso el énfasis en tres aspectos de la disciplina geográfica: en lo cuantitativo, en lo político y en lo histórico.

En sus estudios de la demografía se apoyó Humboldt fuertemente en argumentos demográficos cuantitativos. Un ejemplo es su "Ensayo político acerca de Cuba", en el cual, partiendo de las cifras de la población total de las posesiones españolas en América, de 16,785,000 almas, compuesta por 13,509,000 gentes de color (es decir, indios, mestizos, negros y mulatos) y 3,276,000 blancos (y supuestos blancos), entre los cuales los españoles nacidos en la metrópoli apenas alcanzan 150,000, calcula un porcentaje de blancos del 19\%, claramente inferior al porcentaje en los Estados Unidos (del 60\%), y un porcentaje global de blancos en las Américas del 38\%, "Humboldt saca como conclusión que la sociedad hispanoamericana de los años 1820-1825 presenta una estructura totalmente original y muy diferente de la que presenta la América inglesa" (Minguet, 1985, II: 238) que "la costumbre de vivir en un país donde los blancos son tan numerosos como en los Estados Unidos, ha influido de manera singular en las ideas que han surgido sobre la preponderancia de las razas en diversas partes del Nuevo Continente. Se ha disminuido arbitrariamente el número de los negros y de las razas mixtas" (Humboldt, 1930, II: 395),

En su mejor conocido "Ensayo político sobre el Reino de la Nueva España”, el título revela con toda claridad la importancia del aspecto político, aunque sea posiblemente una obra de "economía política" (como sostiene Labastida, 1981: 15), pero la geografía ocupa un lugar importante como una especie de telón de fondo, pues las 33 páginas del primer capítulo son dedicadas a presentar "consideraciones generales acerca de la extensión y el aspecto físico del Reino de la Nueva España, influencias de las desigualdades del suelo en el clima, la agricultura y el comercio, y la defensa militar del país" (Humboldt, 1991: 3)

Limitándonos a la cuestión de América, en resumen podemos decir que "como geógrafo logra la integración de América dentro de la geografía universal; a partir de Humboldt el continente americano dejó definitivamente de ser considerado un engendro extraño y aberrante de la naturaleza o de la creación. Demuestra la identidad de las estructuras geológicas del Viejo y del Nuevo Mundo y comprueba la unidad del mundo físico y la armonía entre las diversas zonas del cosmos. Ningún aspecto de la geografía pasó inadvertido ante sus ojos: física del mundo, geografía humana, económica y matemática; fitogeografía, etc. Los resultados obtenidos por el sabio alemán sirven todavía de base a los estudios que emprenden los geógrafos de la actualidad" (Minguet, 1985, II: 365).

Con lo multifacético de la obra de Humboldt, vemos la geografía acercándose mucho más que en otros casos hacia la geografía cultural, y de allí hacia la antropología netamente, y con este episodio nos encontramos dentro del periodo que dio a luz las ciencias sociales y naturales en su versión positivista, así también la geografía: "cátedras universitarias normales de geografía fueron establecidas por vez primera en los países de habla alemana en los decenios de 1870 y 1880; algo más tarde en Francia y en Gran Bretaña y en Estados Unidos, generalmente durante el presente siglo" (Hartshorne, 1967: 110). 


\section{El desarrollo de la antropogeografía: El determinismo geográfico}

Pero en nuestra búsqueda de la interacción específica de la geografía y la antropología tenemos que hacer un viaje que empieza en Francia y luego pasa por Alemania y Los Estados Unidos para hacer sus escapaditas a México, un viaje que empieza con el determinismo geográfico para terminar en una rotunda negación de la mera posibilidad de formular un determinismo. El determinismo geográfico tiene muchos orígenes, pero encontró una fuerte expresión, en el contexto de un naciente mundo moderno en Europa, en el pensamiento del pensador francés Montesquieu (Chevalier, 1958).

De manera directa podemos encontrar gran parte de las raíces de la misma antropología en la tradición geográfica alemana que se cristaliza en una "Anthropogeographie" ("geografía humana"), cuyo exponente principal, mas ni el primero ni el único, es Friedrich Ratzel. En su enorme producción -de 25 libros y unos 518 escritos menores- encontramos al mismo tiempo sus declaraciones medulares (sus Elementargedanken, para así decirlo) y la articulación de su geografía con la antropología en tres obras.

El primer volumen de su "Anthropogeographie", publicado en 1882, contiene la más fuerte y concentrada expresión de una relación causal y unidireccional entre las características del ambiente y la vida social y cultural, la más pura expresión de un determinismo geográfico. El segundo volumen de la misma obra, publicado hasta en 1891, es dedicado al estudio de la distribución en el espacio de los pueblos y culturas, y su migración, y contiene elementos de evolucionismo igual que de difusionismo. En este segundo volumen el tono determinista es mucho menos fuerte, y en momentos se llega casi a una dialéctica de la naturaleza y la vida social y cultural.

Un tono muy diferente encontramos en la última de sus obras grandes, la "Geografía política" de 1897, donde el Estado es presentado desde un punto de vista organicista, con su propia vida y dinámica. Las palabras clave de la obra son "Raum" (espacio) y "Lage" (situación), y "desde este punto de vista, los estados funcionan como organismos, no pueden quedar encerrados dentro de unos límites rígidos, y la supervivencia de una nación o cultura va unida a su capacidad de expansión" (Mikesell, 1967: 95-96). No es culpa de Friedrich Ratzel que esta doctrina del estado con mucha facilidad se prestaba a la pseudofilosofía expansionista de Hitler, basada en el concepto de "Lebensraum" (espacio de vida), una distorción que fue hecha por Karl Haushofer y sus seguidores dentro de la Escuela de “Geopolitik" en el Tercer Reich, supuestamente inspirados por el filósofo político sueco Kjellén (1924).

Entre 1885 y 1888 publicó Friedrich Ratzel los tres gruesos tomos de su "Völkerkunde"1 en los que presentó su doctrina del determinismo geográfico con énfasis en los rasgos culturales y las características sociales de un gran número de "pueblos exóticos", con una enorme cantidad de datos etnográficos que, no obstante que el conocimiento etnográfico antes de 1880 era limitado y lleno de errores, todavía hoy inspira respeto (como señala Steinmetzler, 1956).

La antropogeografía alemana, o sea el determinismo ambiental de Ratzel, tendría su continuación en los EE. UU. a través de la obra de Ellen Churchill Semple que en algún momento de su vida fue alumna de Ratzel en la Universidad de Leipzig, donde tuvo que esconderse, pues en aquellos tiempos no se les permitía a las mujeres estudiar en la universidad. Algunos opinan que "el determinismo de Ratzel estaba moderado por

1 La palabra "Völkerkunde" (literalmente "conocimiento de los pueblos") es otra contribución a la confusión terminológica que aqueja la antropología: en Alemania corresponde a la antropología social británica, la antropología cultural norteamericana y la etnología francesa, oponiéndose a la palabra "Volkskunde" (literalmente "conocimiento de un pueblo") que corresponde grosso modo al concepto de "sociología". 
una perspectiva histórica, y formuló reservas en torno a esta relación hombre-tierra; por esta razón no merece del todo la etiqueta de determinista. Es indudable que, en el mundo anglosajón, esta etiqueta es más apropiada para Ellen (Churchill) Semple, que estudió con Ratzel durante el sexenio de 1890 y publicó un importante libro basado en el primer volumen de la Anthropogeographie (Semple, 1911)" (Mikesell, 1969: 95).

Pero otro eslabón importante que asegura la transmisión del pensamiento geográfico alemán a la nueva ciencia antropológica en los Estados Unidos es Franz Boas, alemán de nacimiento pero norteamericano por adopción, científico natural y geógrafo por formación inicial pero eminente antropólogo por decisión propia posteriormente.

Franz Boas inició su trabajo de campo con un planteamiento formulado en términos del determinismo geográfico, zarpando en junio de 1883 de Hamburgo a bordo del vapor alemán "Germania", rumbo a Canadá. Sobre todo en lo geográfico, la preparación de Boas era estremadamente sólida, pues "entre 1878 y 1879 se dedicó al estudio de la geografía y la investigación polares en la Universidad de Bonn; después se adiestró en la observación meteorológica, astronómica y magnética bajo la instrucción de J. M. Förster del observatorio en Berlín; medición antropológica bajo la enseñanza de Rudolf Virchow, así como la lengua danesa y esquimal (inuit) con el apoyo del lingüista Heydrich Steinthal, y consultó las colecciones árticas en los diferentes museos de Berlín" (Korsbaek, 1997: 181).

En uno de sus artículos más importantes, con el título significativo de "The Study of Geography” ("El estudio de la geografía"), Franz Boas, escribiendo todavía como geógrafo, introduce ya el estudio de la alteridad, clave de su futuro estudio antropológico: "antes, cuando una gran parte de la superficie de la tierra era desconocida, y los navíos europeos navegaban solamente por sus rutas bien conocidas, de continente a continente, cuidadosos de no desviarse de su rumbo y miedosos de los peligros de regiones desconocidas, la mera idea de esos territorios enormes que nunca habían sido vistados por europeos podría llenar la mente de un geógrafo con un ardiente deseo de conocimientos más extensos" (Boas, 1887: 639).

Introduce también una de las palabras clave de su nueva orientación antipositivista y neokantiana, que viene a sustituir cualquier posible vestigio de un anterior positivismo, la comprensión: "con el deseo de revelar los secretos de regiones hechos vivos por la imaginación y con figuras de gentes y animales desconocidos; pero entre más completamente conocido sea el contorno de continentes e islas, más fuerte se hacía el deseo de comprender los fenómenos de las regiones recientemente descubiertas, comparándolas con las de las tierras de uno mismo" (Boas, 1887: 639).

En la etnografía de Franz Boas, que en aquellos años estableció un estándar máximo de la calidad etnográfica, sirve la descripción geográfica de trasfondo general en sus notas acerca de la "etnografía kwakiutl" (en efecto, el título del primer capítulo es "Setting and Background", Boas, 1966: 7-15). Después de declarar que "la Costa Pacífica de América, entre el Estrecho de Fuca y la Bahía Yakutat, es habitada por un gran número de tribus indios que son distintas en características y hablan diferentes lenguas, pero se asemejan en cultura" (Boas, 1966: 7), presenta las características geográficas, siempre con una vista a sus implicaciones para las condiciones de vida de los habitantes: "la región habitada por esas gentes es una costa montañosa entrecortada por innumerables estrechos y fiordos y tachonada de islas, grandes y pequeñas, así que la comunicación a lo largo de la costa por medio de canoas es muy fácil, mientras que el acceso a la tierra firme es difícil debido a las colinas accidentadas y lo espeso del bosque; unos pocos fiordos se entierran profundamente en el continente y los valles que se abren hacia ellos dan acceso al corazón de las altas cordilleras que separan la costa de la tierra interior, conformando una barrera efectiva entre 
las gentes de la tierra interior y las de la costa" (Boas, 1966: 7). Apreciando la espesa etnografía que sigue, se aprecia fácilmente que esta sería incomprensible sin la "setting and background" geográfica.

El primer alumno de Franz Boas, Alfred Louis Kroeber, hizo alrededor de 1940 una mayor contribución a lo que podemos llamar la geografía antropológica, con el desarrollo del concepto de área cultural y su aplicación concreta en el análisis de los continentes americanos. Por un lado, es curioso que un antropólogo como Kroeber, con su conceptualización extremadamente idealista de la cultura como "lo superorgánico" (Kroeber, 1917), se dedique a estudiar la organización del espacio geográfico pero, por otro lado, ya en un trabajo anterior acerca de las culturas indígenas de California había planteado una regionalización en base a una síntesis de los rasgos culturales de esos indígenas (Kroeber, 1925). En su reorganización del espacio geográfico y cultural de América del Norte distingue Kroeber siete "áreas culturales" y en cada una de ellas (con la excepción del esquimal), partiendo de la suposición de que "por un lado, la cultura puede ser comprendida primariamente sólo en términos de factores culturales; pero por otro lado ninguna cultura es totalmente inteligible sin referencia a los factores no culturales, a los factores del medio ambiente con el que está en relación y la condicionan” (Kroeber, 1939: 205).

Otro alumno de Franz Boas, Carl Ortwin Sauer, vino a completar el cuadro de esta fuerte inspiración alemana en la encrucijada de la geografía y la antropología. Sauer nació en 1889 en el Deep South, en Missouri pero, como muchos de los tempranos científicos sociales en los EE. UU., nació en el seno de una familia de inmigrantes alemanes. Así que, como la cosa más natural, empezó a estudiar en Alemania en 1906 y en 1908 se graduó en el Central Wesleyan College, para posteriormente terminar su formación en la Universidad de Chicago (Claval, 1974).

El mismo año que Kroeber publicó su Handbook of the Indians of California, una especie de geografía lingüística y cultural de la California nativa, publicó Sauer una de sus primeras incursiones dirigida hacia el estudio del espacio: The Morphology of Landscape y posteriormente, aproximadamente al mismo tiempo que Kroeber empezó a interesarse seriamente por la relación entre el espacio y la cultura.

\section{Geografía, geopolítica e historia de las mentalidades}

Como un cómodo puente para llegar a discutir la relación entre la antropología y la geografía, podemos utilizar la historia de las mentalidades, pues, por un lado esta disciplina realmente "es una especie de antropología" (Korsbaek, 2000), ni más ni menos y, por otro lado, es una disciplina histórica que está permeada por puntos de vista geográficos. Después de haber administrado cordialmente una serie de patadas a las tradiciones anglosajón y alemana, un historiador francés plantea el dilema de la siguiente forma: “¿será preciso, para ser historiador, olvidar la utilización del suelo, y para ser geógrafo, olvidar el pasado? la geografía histórica lo sería entonces todo, es decir nada" (Raison, 1988: 234).

Yaque unode los fundamentos de la historia de las mentalidades es su interdisciplinariedad, no puede sorprendernos que entre sus fundadores encontremos a varios geógrafos y, ya que otro de sus fundamentos es la negación del determinismo, tampoco es inesperado que la visión geográfica que encontramos a la raíz de la historia de las mentalidades se manifiesta como una protesta contra la anthropogeographie fuertemente determinista de Friedrich Ratzel (Ratzel, 1889).

El personaje en el cual se cristalizan estas características y que viene a dar un fuerte impulso geográfico a la historia de las mentalidades es el francés Pablo Vidal de la Blache -y tampoco es raro que es francés ya que, no obstante la difusión mundial de la 
historia de las mentalidades, nació como un movimiento francés-. ${ }^{2}$ Vidal de la Blache era aproximadamente contemporáneo con Emile Durkheim, con quien tenía al mismo tiempo coincidencias y desacuerdos, y como él, estudió también en la Escuela Normal Superior en París. Uno de los profesores en la Escuela Normal Superior era Fustel de Coulange, debido a su influencia el joven Vidal de la Blache se inclinó hacia los estudios históricos y terminando sus estudios en la Escuela Normal Superior se marchó a Grecia a preparar su Tesis Doctoral sobre las toponimias griegas en Asia Menor.

Formalmente la historia de las mentalidades nace hasta el 15 de enero de 1929 (así que todo lo hasta aquí mencionado refiere a sus precursores), bajo la dirección de Marc Bloch y Lucien Febvre, con la publicación del primer número de su revista que será después conocida como los Annales d'histoire économique et sociale, un nombre que supuestamente se debe a los Annales de géographie fundados por Vidal de la Blache en 1891. ${ }^{3}$

Los dos fundadores de la historia de las mentalidades eran Lucien Febvre y Marc Bloch y, sobre todo, en la obra de Lucien Febvre reconocemos al mismo tiempo una historia que es netamente de las mentalidades y que se relaciona íntimamente con la geografía, tanto como disciplina como en cuanto campo de trabajo. En cuanto al carácter mentalista de la historiografía de Febvre, es de notar que todas sus obras giran en torno a un destino, pero visto en su contexto social y cultural: Lutero (Febvre,1956), Rabelais (Febvre, 1942), Margarita de Navarro (Febvre, 1944), Erasmo de Roterdam, contrapartida de Lutero (Febvre, 1985) 5 .

Lucien Febvre era ya condenado por su herencia: tenía veinte años cuando fue publicada la biblia de la historiografía positivista, la Introducción a los estudios históricos de Langlois \& Seignebos, en 1898, con lo que ya tenía definido al enemigo. Pero lo salva su insistencia en la interdisciplinariedad, y su historia es una historia literalmente permeada por geografía. En 1933 contesta a un amigo, en una carta con el significativo título "contra el espíritu de especialidad”: "me dice usted: ¿en dónde está la geografía?, mi querido amigo: la geografía está en todas partes y en ninguna" (Febvre, 1993: 160). Sus ricas fuentes de inspiración encuentra en sus amigos historiadores, Henri Berr, geógrafos, economistas, politólogos, etc.

2 El movimiento francés de la Historia de las Mentalidades, que no es propiamente una escuela, sino "una nebulosidad en expansión” (según Couteau-Bégarie, 1983: 259), es presentado con redondez en Burke, 1999, pero hoy es articulado con la historia social británica (véase Hobsbawm, 1979 y Briggs, 1989), y en los EEUU encontramos una articulación en algunas herencias de la Historia de las Ideas de Lovejoy, de quien son seguidores Robert Nisbet (1969) y, con un grano de sal, Clifford Geertz (1987, 1994), sobre todo a través del alumno de Geertz, Robert Darnton (1987). Pero la historia de las mentalidades ha sabido guardar gran parte de su sabor francés.

3 Los Annales se llamaron originalmente Annales d'Histoire économique et sociale, y en primera instancia se le había invitado a Henri Pirenne a dirigir la revista pero, ya que este inclinó la invitación, los dos creadores de la revista, Marc Bloch y Lucien Febvre, se encargaron de la dirección. La revista pasó por cuatro periodos, con dominación y tendencia muy variadas. Al principio era una revista con material principalmente económico y de carácter contestatario ("es necesario ser herético", Febvre, 1993: 16), pero después de la guerra se hizo ortodoxa ("la revista se transformó en el órgano oficial de una iglesia ortodoxa", Burke, 1999: 37; a Lucien Febvre se le aplicaron epítetos eclesiásticos: al principio era un "prelado combativo", según Raulff, 1988, al final era "el Febvre pontifical”, según Hughes, 1969).

4 Donde Febvre formula así su propósito: “dibujar la curva de un destino que fue sencillo pero trágico; situar con precisión los pocos puntos verdaderamente importantes por los que pasó; mostrar cómo, bajo la presión de qué circunstancias, su impulso primero tuvo que amortiguarse y su trazo primitivo desviarse; planteara así, a propósito de un hombre de una singular vitalidad, el problema de las relaciones del individuo con la colectividad, de la iniciativa personal con la necesidad social, que es, tal vez, el problema capital de la historia: tal ha sido nuestro intento" (Febvre, 1956: 9).

5 Donde Febvre busca en el personaje de Erasmo de Roterdamo, y sus relaciones con su contemporaneidad, "la solución de una cuestión importante y discutida: nada menos que la cuestión de los orígenes, si no del mundo, al menos del espíritu moderno" (Febvre, 1985: 197). 
Ya en 1922 Lucien Febvre había publicado una obra con un título que no nos deja dudar de su interés: La tierra y la evolución humana. En "este extenso ensayo, que molestó a algunos geógrafos profesionales porque era obra de un extraño a esa actividad, desarrollaba las ideas del antiguo maestro de Febvre, Vidal de la Blache", oponiendo frontalmente a las ideas deterministas de Ratzel y declarando que la geografía se trata "des nécessités, nulle part; des possibilités, partout" ("de necesidades, en ningún lugar, de posibilidades, por todos lados", Febvre, 1922: 284). En un capítulo del libro, donde trata los caminos y los ríos, los trata al mismo tiempo como obstáculos y como medios de comunicación, y no se le olvida tratar los caminos de las peregrinaciones (Febvre, 1922: $402 \mathrm{ss).}$

Algunos años después de la obra de Vidal de la Blache nace propiamente lo que es hoy la historia de las mentalidades. Es costumbre dividir la genealogía de esta historia en cuatro generaciones, de las cuales los padres fundadores, Lucien Febvre y Marc Bloch, son los integrantes de la primera generación.

En este contexto le tocaría a un alumno de Vidal de la Blache afinar este método histórico geográfico. Lucien Febvre, a través de lo que llamó análisis histórico de la evolución de las agrupaciones humanas, decía que "el geógrafo debe auxiliarse en los documentos; pero lo que debe pedirles no es que le informen sobre el papel del suelo en esta evolución, ni sobre la influencia que las condiciones geográficas han podido ejercer en el transcurso del tiempo sobre los destinos y la historia de los pueblos; sino más bien, que le ayuden a determinar qué acción han podido ejercer los pueblos sobre el medio. Esto para explicar los fenómenos geográficos de los que el hombre ha sido testigo o artífice, así es indispensable estudiar con ayuda de los documentos, estudiar la evolución del paisaje desde el pasado" (Febvre, 1955).

Lucien Febvre no deja a nadie en dudas acerca de su opinión del determinismo geográfico, un platillo de un sabor muy alemán: “¿Determinismo geográfico? ¿Qué molinos de viento son éstos? ¿Quién le da aún crédito? ¿Quién los menciona todavía? Y así se van sucediendo los textos, correctos, irreprochables, todos señalando acusadoramente a un determinismo ciego y riguroso. Sin duda lo es. No obstante, recordemos una vez más aquel texto de Ratzel; de ese Ratzel que no es cualquier bisoño principiante, de ese mismo Ratzel que, por razones que no cabe esclarecer aquí, recientemente algunos geógrafos franceses empujaban de muy buena gana a la cabeza de grupo. Merece, pues, volver a citarse ese texto sobre el suelo que, "siempre igual, y siempre situado en el mismo punto del espacio, sirve como soporte rígido de las aspiraciones cambiantes de los hombres"; es él, dice Ratzel, el que "rige el destino de los pueblos con una brutalidad ciega", cuando éstos "llegan a olvidar este sustrato, les hace sentir su primacía y les recuerda, con sus graves advertencias, que toda la vida del Estado tiene sus raíces en la tierra"; y el axioma final, que no hay que olvidar: "un pueblo debe vivir sobre el suelo que ha recibido del destino, debe morir en él y someterse a su ley" (Febvre, 1970: 25). En esta cita expresa Lucien Febvre con burbujeante elocuencia un número de hechos: que Ratzel es el padre del determinismo geográfico, que este determinismo geográfico tenía en sus tiempos influencia entre los geógrafos franceses, y que Lucien Febvre no está de acuerdo con la posición determinista, en absoluto.

Advertía en este trabajo que "el que estudia la acción de las condiciones geográficas sobre la estructura de los grupos sociales corre peligro de perderse. Es decir, de atribuir un valor primordial y decisivo a las condiciones geográficas. pero si se invierten los términos y se pregunta no cuál es la acción de los grupos sociales sobre el medio geográfico, sino con mayor precisión: qué rasgos de un paisaje dado, de un conjunto geográfico apreciado directamente o reconstruido por medio de la historia, se explican o pueden explicarse por la acción continua de un grupo determinado o de una cierta forma de organización social... 
Si el autor de una monografía regional de horizonte bastante estrecho se abstiene de toda comparación, y abarca en sus explicaciones un número excesivo de hechos, correr el riesgo de equivocarse acerca de las relaciones que pretende establecer entre tales caracteres geográficos y tales fenómenos sociales (Según Berr, citado en Febvre, 1955). Para Febvre todo este tejido en el paisaje en esta realidad única, y la causa determinante consiste en un total indefinido de condiciones. Si queremos hacer obra eficaz no importa ser geógrafo, historiador o sociólogo, debemos dedicarnos a la misma tarea lenta, tentativa y difícil de la construcción de la verdad, para un mejor discernimiento.

Para Febvre no existe geografía política e histórica sin geografía social, ni geografía social sin geografía económica, ni geografía económica sin geografía física, lo muestra como un encadenamiento que en vano se trataría de romper. Así que son obligaciones para el que hace geografía humana realizar trabajos que suponen un largo aprendizaje, una larga iniciación que enseña el estrecho lazo, la dependencia directa de la geografía humana respecto de la geografía física.

El aporte final de la corriente histórica de Febvre fue la atención que el geógrafo debe prestar a los medios de subsistencia, de crecimiento material, su dominio económico sobre el uso del suelo y de los recursos, su estructura y desarrollo interno y su conexión externa, y sobre todo su imprenta o huella que esto deja en la transformación y formación de paisajes, son cuestiones que se deben estudiar de cerca, según Febvre, si se quiere apreciar la influencia profunda y múltiple de la geografía en el desarrollo del territorio y de las poblaciones que lo ocupan. Así, Febvre define con rigor la tarea de la geografía humana respectiva la cual que llega hasta la prehistoria: "las relaciones que han mantenido las sociedades humanas en otros tiempos, en diversas épocas, en los distintos lugares del globo, con el medio geográfico de su tiempo, como tal como intentar reconstruirlo" (Febvre, 1955). Podemos decir, entonces, que el gran mérito de Lucien Febvre fue el de someter a una crítica implacable las idas vagas, las leyes discutibles, las afirmaciones absolutas, que se habían empleado precipitadamente y los conceptos simplistas que empobrecen la realidad viviente.

La segunda generación de esta historia de las mentalidades es por completo dominada por Ferdinand Braudel, que ha sido caracterizado como un "déspota benigno" y que llegó al extremo de llamar su estudio histórico geopolítica, y lo vemos en prácticamente toda su producción: "el representante más importante de esta nueva situación fue Ferdinand Braudel, cuya obra en constante evolución muestra una serie de saltos cualitativos muy significativos desde la primera versión del Mediterráneo hasta su obra magistral sobre la Civilización material" (Cortez, comp., 1991: 14, haciendo referencia a Braudel, 1984 \& 1992).

Es sabido que la obra de Braudel sobre el Mediterráneo en tiempos de Felipe II se mueve en tres tiempos: la tercera parte de la obra es dedicada a la historia de los acontecimientos, es decir la corta duración, la segunda parte dedicada a los procesos de la mediana duración, los "destinos colectivos y movimientos de conjunto", mientras que la primera parte trata los movimientos muy lentos, de la larga duración, bajo la etiqueta de "la influencia del medio ambiente". Es sobre todo en la primera parte que confluyen el tiempo y el espacio, la historia se convierte en estudio de geografía.

En esta primera parte, dedicada al Mediterráneo que Braudel "ama apasionadamente", como dice en el prólogo a la primera edición, y que "trata de una historia casi inmóvil, la historia del hombre en sus relaciones con el medio que le rodea; historia lenta en fluir y transformarse" (Braudel, 1992, I: 17) nos presenta primero, en el capítulo 1, el paisaje seco: "las penínsulas: montañas, mesetas, llanuras" y luego, en el capítulo 2, el paisaje mojado: 
“en el corazón del Mediterráneo: mares y litorales", para irse a la periferia en el capítulo 3: "los confines: el Mediterráneo mayor", en el que trata las regiones que no pertenecen al Mediterráneo pero que sí repercuten sobre su destino; luego empieza a amarrar cabos, en el capítulo 4 "la unidad física: el clima y la historia", y en el capítulo 5 "la unidad humana: rutas y ciudades, ciudades y rutas". En estas 468 páginas presenta el trasfondo geográfico del drama histórico que se desarrolla en tres tiempos, de los cuales la duración larga corresponde a estos cinco capítulos, como señala Braudel con las primeras palabras en esta primera parte: "como su título indica, la primera parte de este libro se centra en torno a la geografía. pero es una geografía muy sui generis, atenta especialmente a cuanto concierne a los factores humanos. Y no sólo eso: es también un intento de dar con una particular especie de historia" (Braudel, 1992, I: 27).

Le Roy Ladurie ha contribuido también una especie de cartografía mundial de los microbios donde concluye, invocando a Woodrow Borah, que "las bacterias y los virus, en efecto, hicieron efectiva la unidad del globo aún antes que el hombre hubiera logrado realizarla por su propia cuenta" (Le Roy Ladurie, 1988: 65).

\section{La geografía en la antropología}

Teniendo en mente que la antropología no es geografía, no obstante el lugar importante que ocupa la geografía cultural en el desarrollo histórico de la antropología, la geografía es omnipresente en el quehacer antropológico, de muchas diferentes maneras.

Un temprano travelogue, "Anahuac, or Mexico and the Mexicans, Ancient and Modern" que publicó uno de los padres fundadores de la antropología, Edward Burnett Tylor, en 1861, antes de decidir dedicarse a la antropología, está lleno de observaciones geográficas y el autor nos presenta una hermosa descripción del Valle de México y leemos que "el México de Moctezuma está encapsulado en una idea bien definida. El anfiteatro de colinas oscuras que rodean la planicie lisa, los dos picos de montaña cubiertos de nieve, los cinco lagos que cubren casi la mitad del valle, y la ciudad que se levanta en medio del agua, millas alejada de las riberas con las que estaba articulada por medio de sus cuatro calzadas, las calles rectas con casas bajas con techos planos, el número de canales atascados de indígenas yendo y viniendo del mercado, los jardines flotantes que se movían de lugar a lugar y en los cuales se cultivaban vegetales y flores, la gran pirámide sobre la cual los españoles vieron a sus compañeros capturados llevados en procesión solemne para ser sacrificados en la cima -todos estos son detalles de la imagen mental que tenemos de México y su conquista"; este paisaje coloca Tylor después en el contexto de su propia actualidad, hace unos cientocuarenta años: "casi todo eso ha cambiado desde el día en que los españoles lo vieron por primera vez. Cortés intentó por todos los medios ordinarios vencer la desesperada obstinación con la que los aztecas defendieron su capital. Los españoles conquistaron por todos lados pero como avanzaron los mexicanos volvieron a cerrar el círculo detrás de los españoles, y de cada techo ráfagas de flechas, lanzas y piedras fueron tiradas contra ellos. Cortés decidió proceder hacia la destrucción total de la ciudad. Estaba afligido al tomar la decisión pues, decía el, era la cosa más hermosa en todo el mundo, pero no había alternativa. Avanzaba lentamente hacia el gran teocalli, seguido por sus cincuenta mil aliados tlaxcaltecos, allanando cada casa y llenando los canales con las ruinas. Cuando la conquista estaba ejecutada quedaba solamente un distrito de la ciudad intacto, y en él estaba atascada la cuarta parte de la población de la ciudad, miserables hambrientos que se habían rendido cuando fue capturado su rey " (Tylor, 1861: 40-41).

La importancia del sistema de Valle de México, especialmente el mercado de Tlatelolco, en el abastecimiento de alimentos a Tenochtitlán (capital de los mexicas), es indicado por 
el hecho de que una de las primeras acciones de Cortés después de conquistar la ciudad fue mandar a que los mercados estuvieran organizados como antes, para asegurar el abastecimiento de la ciudad. Y se ha calculado que los 150,000/200,000 habitantes de la ciudad capital obtenían aproximadamente el $40 \%$ de sus alimentos por el sistema de mercado (el resto venía de tributo, renta e impuesto)".

En los estudios ecológicos, que parten de la formulación del concepto de ecosistema, y un ejemplo de un tal estudio ecológico es el artículo pionero que Sol Tax publicó en 1937, en el cual estudió la institución que posteriormente sería conocida como "el sistema de cargos": La geografía de la región es simple. La divisoria continental atraviesa diagonalmente el centro, donde la altitud alcanza 3000 metros y no baja de 2500 (cerca de 8200 pies). Hacia el norte de la divisoria la declinación es gradual y poco considerable, en tanto que en el sur hay un rápido descenso hacia la costa del Pacífico. Las tres características más sobresalientes de la geografía física son:

1) La fila de volcanes que marca el descenso hacia la costa del Pacífico. Ellos forman una barrera en el paso del altiplano a la costa y limitan estrictamente el número de rutas comerciales.

2) El lago de Atitlán, que algunos geólogos afirman que es un cráter, mientras otros dicen que fue formado por el estancamiento de aguas fluviales, provocado por el surgimiento de los volcanes situados al sur de dicho lago, tiene mucha importancia como medio de transporte y no constituye una barrera en las comunicaciones.

3) Las grandes irregularidades de altitud debidas a la estructura general, los cerros y los numerosos barrancos que interrumpen tanto la superficie de las colinas como la de las llanuras, son realmente las barreras para el tráfico, aun cuando en un grado notable son dominados" (Tax, 1937: 91-92).

Un estudio más famoso es la monografía de los Argonautas del Pacífico Occidental de Malinowski, en el cual describe y analiza un mercado no occidental. Su minuciosa descripción del ambiente en el cual se desarrolla el tema de su monografía es netamente geográfica: "El mapa II, aquí adjunto, muestra el distrito kula, es decir, la punta más oriental de la isla mayor y los archipiélagos situados al este y al nordeste. Tal como dice el profesor C. G. Seligman: "Esta área podría dividirse en dos partes, una pequeña sección septentrional que comprende las Trobriand, las Marshall Bennett, las Woodlarks (Murua) y cierto número de islas más pequeñas, como las Laughlan (Nada), y una porción meridional mucho mayor que comprende el resto de los dominios de los massim". Esta división se señala en el mapa III con la línea gruesa que deja al norte las Amphlett, las Trobriand, el pequeño grupo de las Marshall Bennett, la isla de Woodlark y el grupo de las Laughlan. Me ha parecido conveniente dividir la sección sur en otras dos partes, según una línea que deja al este la isla de Missima, la isla del Sudeste y la isla de Rossel. Dado que la información sobre este distrito es sumamente escasa, he preferido excluirlo del área meridional de los massim. De toda esta área excluida, sólo los indígenas de Missima intervienen en el kula, pero su participación es muy poco estudiada en el presente trabajo. El segmento occidental -y esta es la región a la que denominaremos distrito de los massim meridionales- comprende, en primer lugar, la punta oriental de la tierra firme (de Nueva Guinea) y unas cuantas islas adyacentes, Sariba, Roge'a. Side'a y Basilika; al sur, la isla de Wari; al este el importante, aunque pequeño, grupo de Tubetube (grupo de Engineer); y al norte el gran archipiélago de las islas d'Entracasteaux. De este último, sólo un distrito, el de Dobu, nos interesa de manera específica. Las tribus, culturalmente homogéneas, de los massim meridionales corresponden al distrito $\mathrm{V}$ de nuestro mapa y los dobueses al distrito IV" (Malinowski, 1973: 47, citando a Seligman, 1910: 7). Pero la geografía que nos 
presenta Malinowski es de un tipo particular, pues "toda la descripción del kula se presenta, pues, por así decirlo, desde la perspectiva trobriandesa" (Malinowski, 1973: 49), lo que hoy es bastante normal en la antropología; en 1922, cuando fue publicada originalmente la monografía de Malinowski era hasta tal grado una novedad que cambiaría todo el curso de esta disciplina.

Lucien Febvre postuló y demostró en su estudio de la religión de Rabelais que solamente con el inicio del mundo moderno nació la necesidad de medir el tiempo con precisión matemática (Febvre, 1942) y, de la misma manera, mostró Elsie Clews Parsons en su estudio de Mitla en Oaxaca que la concepción tradicional del espacio era una concepción que carecía de la precisión matemática de nuestro mundo moderno, pero empapada en simbolismo (Parsons, 1936). En un estudio pionero de la restitución de la identidad étnica concluye Carmagnani que "en el curso de los siglos XVII y XVIII el espacio es percibido concretamente como una serie de puntos -cerros, cuevas, iglesia, pueblo, milpa- a los cuales los individuos y la comunidad pueden constantemente hacer referencia. A partir de esta idea extremadamente concreta del espacio, cuyo fundamento es la alianza establecida entre la divinidad y la comunidad, se estructura la idea de un territorio étnico diferente de la idea de territorio político-administrativo colonial. ... siendo el territorio étnico una dimensión derivada de la sacralidad del espacio, termina por ser él también sagrado y susceptible, por lo tanto, de ser ordenado, regulado, a imagen y semejanza del espacio divino. De este modo, los habitantes del territorio terminan por atribuirle un significado inmaterial" (Carmagnani, 1988: 49-50).

Propiamente antropológica es una visión "émica" del espacio. ${ }^{6}$ Un trabajo pionero fue hecho por E.T. Hall en los años sesenta, cuando empezó a estudiar de qué manera las gentes manipulan el espacio de acuerdo a su propia visión, culturalmente específica, del mismo espacio: "he acuñado la palabra proxémica para designar las observaciones y teorías interrelacionadas del empleo que el hombre hace del espacio, que es una elaboración especializada de la cultura", escribió en 1966, dejando clara su deuda para con la antropología: "los conceptos aquí expuestos no son originales míos; hace más de treinta años, Franz Boas puso las bases de la opinión que tengo" (Hall, 1989: 6).

De esta manera es fácil distinguir las diferencias entre el uso del espacio en ciudades occidentales y modernas, a distinción del uso del espacio por ejemplo en una comunidad indígena donde la naturaleza no es considerada como una enemiga a subyugar, sino como una extensión de la misma arquitectura humana. Ya unos años antes había definido los fundamentos de su enfoque: "el hombre ha desarrollado su territorialidad hasta un punto casi increíble; no obstante, de algún modo tratamos el espacio como tratamos el sexo: está ahí, pero no se habla de él" (Hall, 1990: 174).

A continuación de los estudios pioneros de E.T. Hall, recientemente mucha energía antropológica se ha dirigido hacia el estudio de la concepción y el uso del espacio en contexto ritual de las comunidades indígenas en México y en otras partes del mundo. Algunos de estos estudios se deben a Evon Z. Vogt, el fundador y director del Proyecto Harvard en Chiapas. En Zinacantán, por ejemplo estudió el uso que hicieron los habitantes del espacio en su comunidad para los rituales relacionados con el sistema de cargos $\mathrm{y}$, trasladándose a una dimensión histórica, buscaba la continuidad entre el uso de preconquista y el uso actual de este espacio.

6 Los conceptos "émico" y "ético" pertenecen al acervo teórico y metodológico de la antropología. El misionero-lingüista Kenneth Pike formuló originalmente este par de conceptos, pirateando parte de los conceptos lingüísticos fonémico/fonético y creando así los dos conceptos. La visión émica es la visión "desde dentro", es decir desde el punto de vista de un miembro de una cultura dada, de un fenómeno que pertenece a esta cultura, mientras que la visión "ética" es la visión del mismo fenómeno, pero desde fuera, con los ojos de una persona ajena a la cultura en cuestión, por ejemplo un antropólogo. 
El estudio antropológico del espacio tiene escala e, igual que Ferdinand Braudel ha formulado una distinción entre la duración corta, la mediana y la larga, en la dimensión geográfica de la antropología podemos hacer una distinción entre la perspectiva micro, la perspectiva media y la perspectiva macro, señalando la diferencia entre un estudio de un espacio reducido e íntimo, como el espacio de un hogar, y un espacio más grande como una región y, al final, la extensión de una región muy grande, de aquellas que llamamos "área cultural" y que abarcan una considerable parte de un continente si no un continente entero.

"El concepto de área cultural se ha vuelto una herramienta tan importante en las operaciones de los antropólogos que al cuestionarla pareceríamos sembrar dudas acerca de la antropología misma", declara Steward (Steward, 1979: 79), depués de hacer a un lado el concepto de Kulturkreis de los difusionistas (principalmente alemanes) y constatar que las influencias británicas de Malinowski y Radcliffe-Brown "aunque provocadores de nuevas ideas, no han llevado a clasificación sistemática alguna".

\section{La antropología geográfica: La perspectiva micro}

Siguiendo las pistas de Hall y Bourdieu, podemos encontrar un estudio de la distribución y del uso del espacio, partiendo del hecho que la antropología es antes que nada el estudio de la cultura y buscando lo que nos interesa en la encrucijada entre las diferentes ramificaciones del concepto de cultura (que no son pocas) con los estudios geográficos del espacio.

Una tal línea encontramos en el estudio del paisaje cultural, un estudio cuyo desarrollo histórico se manifiesta como un conflicto entre una arraigada tradición positivista y una fuerte reacción contra esta tradición. Denise Brown señala que "la escuela más importante dentro de esta disciplina propone entender el paisaje, en la primera instancia, como un medio natural, que puede ser descrito con base en sus aspectos físicos empíricamente observables. El uso clásico del término y concepto de paisaje (landscape) enfatiza este aspecto objetivo, partiendo del supuesto de que existe una observación pura, sin influencia cultural ni personal de parte del observador" y agrega más interesantemente que "en el siglo pasado, la escuela de pintura de paisajes, que llegó a su apogeo con pintores ingleses como Turner, adoptó esta perspectiva del paisaje, perfeccionando la representación de escenas de paisaje desde un punto de vista casi omnipresente, es decir, supuestamente libre de juicio humano" (Brown, 1999: 75), contra lo que protesta por ejemplo el pintor René Magritte que dice que "vemos (el paisaje) como si existiera fuera de nosotros, cuando realmente es una representación mental de lo que hemos experimentado por dentro" (según Schama, 1995: 12, citado en Brown, 1999: 75).

Sería interesante buscar las perspectivas antropológicas entre los diez enfoques que sugiere Meinig para el estudio del paisaje: 1) la naturaleza, cuando se minimiza o se elimina a la gente del paisaje, 2) el hábitat, observando cómo la gente se adapta a este medio natural, 3) el artefacto, viendo impactos de las actividades del ser humano, 4) proceso, cuando se enfatiza la interacción del ser humano con el medio natural, 5) problema, si se presenta como obstáculo para la vida humana, 6) riqueza, si se ve como recurso y propiedad, 7) ideología, buscando valores culturales y filosóficos, 8) historia, enfocándose en las huellas concretas de actividades humanas a través del tiempo, 9) lugar, si el paisaje observado se compone de sitios con identidades e identificaciones, o bien 10) como estética, si el paisaje se observa en términos de cualidades artísticas (Meinig, 1976, citado en Brown, 1999: 76).

Una línea afín encontramos en los esfuerzos por crear una geografía simbólica, y podemos partir del consejo que les dan los mandan a sus visitantes hidatsa: "viajen hasta 
el norte hasta que ya no puedan ver el humo de nuestros .... y ahí construyan su pueblo; estaremos entonces suficientemente cerca para ser amigos y no lo suficientemente alejados para ser enemigos" (Lévi-Strauss, 1973: 299, citado por Raymundo Mier, 1996: 121) y dedicar nuestra atención a un número de la revista Cuicuilco, dedicado al estudio de "geografías simbólicas".

La distancia entre la antropología y la arquitectura es tan corta que cualquier arquitecto tiene que ser un poco antropólogo y viceversa. Un caso que demuestra las desastrosas consecuencias de ejercer la arquitectura sin antropología, es decir de construir casas sin tomar en cuenta los deseos y las costumbres de las gentes que van a habitar las casas construidas por los arquitectos encontramos en la comunidad Otomí de San Juan Tuxtepec en el municipio de Chapa de Mota, "en donde hace 28 años llegó el programa PRIVICAM, y se les ayudó a los campesinos con posibilidades de adquirir material a construir su casa, poniendo el programa el material y los habitantes la mano de obra y parte del material con que contara la comunidad. Al cambiar de lugar de residencia, los campesinos no pudieron adaptarse a un nuevo tipo de vivienda, pues no contaban con espacio suficiente para la crianza de sus animales y el cuidado de sus cultivos que ya son aproximadamente 60 casas construidas de manera homogénea, por lo que los dueños tuvieron que vender sus casas y regresar a su antigua residencia, actualmente este lugar está ocupado por maestros que trabajan en la comunidad o personas que vienen de otros lugares. La distribución de la vivienda tradicional se da de la siguiente manera: Dos habitaciones, cocina de humo en la parte lateral de estas, una fosa séptica, que está ubicada en el lado posterior a la cocina, el solar está ubicado al frente de las habitaciones o en la parte lateral, y los terrenos de cultivo rodeando regularmente la propiedad. Siendo esta, de menos de media hectárea, por familia". ${ }^{7}$

En esta línea de microgeografía antropológica que colinda con la arquitectura tenemos un trabajo pionero de Pierre Bourdieu que se ha convertido en un clásico: su descripción etnográfica de la casa cabila en el norte de África, donde se hace una descripción y análisis pormenorizados de la distribución de los espacios en la casa y de su uso (Bourdieu, 1970).

Cunningham señala en su estudio de la arquitectura y simbolismo atoni en Indonesia que "La casa puede ser un medio efectivo para comunicar ideas de una generación a la siguiente en una sociedad preliterata; el ritual es un medio similar, aunque tal vez menos efectivo; los atoni de la isla Timor de Indonesia no construyen casas con la intención de comunicar nociones abstractas, construyen hogares; sin embargo, lo hacen de una manera que es enseñada y manejada por los ancianos, de acuerdo a reglas que son consideradas una parte vital de su herencia y las casas siguen un patrón y no un capricho individual" (Cunningham, 1964: 117). Prosigue Cunningham: "cuando estudié la casa atoni, me contaron de qué manera las partes, las secciones y los aposentos fueron utilizados y hechos; los aldeanos son igualmente explícitos, sin embargo, en lo que se refiere a otro aspecto de la casa, el orden según el cual las cosas son colocadas y usadas; cuando se les pregunta por qué es necesario un orden específico, predomina una sola respuesta sencilla: "atoran es ia" (o sea, es el atoran, el orden o el arreglo)" (Cunningham, 1964: 117).

En este contexto es interesante someter los conocimientos de Cristóbal Colón a un análisis antropológico: ¿qué conocimientos tenía él de las diferentes partes del mundo y qué posibilidades poseía él para adquirir conocimientos de las partes todavía en aquel entonces desconocidas? Al respecto es interesante especular acerca de la diferencia entre

7 Cito de un informe de prácticas de campo en las comunidades otomíes en el municipio de Chapa de Mota, con alumnos de la Facultad de Antropología de la UAEM en Toluca, en agosto de 1998. 
lo desconocido, lo inexistente y lo que lógicamente no puede existir, una problemática íntimamente relacionada con la de la alteridad en su contexto histórico. Destaca la relación que se manifiesta en las notas a pie de página escritas por Cristóbal Colón en su ejemplar de los viajes de Marco Polo: dos diferentes experiencias de la alteridad, una dentro de la otra, y la supuesta existencia de un mapa de 1489 -tres años antes del primer viaje de Colón- con claras indicaciones de tal número de detalles geográficos del continente americano que nos vemos forzados a suponer el conocimiento del Nuevo Mundo antes del primer viaje de Cristóbal Colón (Marco Polo, 1984; Vargas, 1996).

\section{La antropología geográfica: La perspectiva media}

Un problema antropológico de carácter geográfico que ha estado presente a través de toda la carrera de la antropología en esta parte del mundo es el problema de la regionalización, un problema que es al mismo tiempo un reto teórico y una tarea netamente práctica.

El Diccionario Enciclopédico de Grijalbo define una región como una "extensión de territorio definida por características comunes (físicas, climáticas, étnicas, históricas, etc.)" (Grijalbo, 1995: 1570), definición que no difiere mucho de otra definición pionera: "Una región es una zona homogénea con características físicas y culturales distintas de las de las zonas vecinas" (Vance, 1976: 161). Ambas definiciones causan inmediatamente tres observaciones: primero, que el concepto de región tiene que ver con la relativa homogeneidad en una extensión territorial dada; segundo, que una región se inscribe en un contexto abarcador, como por ejemplo una región de mayor escala o una nación, y tercero, que la homogeneidad se puede referir a una serie de dimensiones, a título de ejemplo las mencionadas en el Grijalbo: física, climática, étnica, histórica, entre otras.

Acerca de las regiones económicas formula Angel Bassols Batalla los fundamentos teóricos en 7 puntos: 1) que existen objetivamente en la realidad y que son producto de la interacción naturaleza-sociedad, 2) que reflejan las distintas etapas de desarrollo en un territorio concreto y en una época determinada, 3) que, debido a la distribución de los recursos, tienden a conformarse como sistemas y que los límites naturales casi siempre son franjas de transición, 4) que hay cierta coincidencia entre la región natural y la económica, mayor coincidencia entre menor sea el desarrollo tecnológico, 5) que influye fuertemente la distribución de la población a través de los periodos históricos, 6) que en una región hay siempre algún tipo de actividad económica que predomina, y 7) la especialización actual es siempre el resultado de la historia económica (Bassols Batalla, 1979: 24).

Las regiones políticas son, a todas luces, más complicadas, ya que tienen que manejar la sustancia escapadiza que es el poder. Acerca del juego entre el espacio y el poder plantea un investigador francés que "El espacio interviene de diversas maneras en la vida social y, por lo tanto en el juego del poder: 1) es sostén de la vida y de la actividad, e interviene entonces por la extensión; 2) es obstáculo para la vida de relación; 3) sirve de base a la actividad simbólica", explicitando que "a) el espacio interviene en primer lugar por la extensión ... b) como obstáculo para la vida de relación, el espacio vuelve costoso el transporte de los bienes, difícil y lento el traslado de las personas; crea una opacidad de la cual es difícil triunfar ... c) la distancia no es el único elemento que viene a frenar el intercambio de las informaciones; la comunicación se funda en la existencia de sistemas de signos conocidos por quiénes están en conexión" (Claval, 1982: 19-23).

Para definir las seis grandes regiones británicas, Claude Moindrot toma los siguientes pasos: a) define las regiones estructurales (historia geológica y grandes conjuntos geomorfológicos), b) presenta los elementos básicos del clima en Gran Bretaña e Irlanda, c) muestra las variaciones en la historia económica, d) la especialización de la economía 
actual, e) las zonas de influencia regional de las ciudades y f) los aspectos de la planeación regional (A. Colin, 1971), mientras que P. George establece las regiones de los EE. UU. de acuerdo al siguiente procedimiento: a) grandes factores y conjuntos naturales, b) los recursos potenciales, c) formación de la población norteamericana, d) actividades y niveles de vida; ciudades y medio rural; el medio natural y social.

De estos dos procedimientos podemos sacar inmediatamente una conclusión: ya que el hombre interactúa con la naturaleza, y cualquier concepto de región de interés social o cultural, en el sentido más amplio de estas palabras, será una construcción que podemos llamar interdisciplinaria, abarcando y conjugando un número de variables, tiene que partir de las variables que están más lejos del control humano, es decir la geología y los demás rasgos que en su conjunto conforman la región natural, para terminar en lo que se encuentra más cerca del control humano y sujeto a este control en su afán por modificar la naturaleza, es decir lo político y lo cultural.

En la serie de publicaciones acerca de la distribución regional de la población indígena en los estados de la República, el Instituto Nacional Indigenista ha formulado un método de análisis regional que se basa en la existencia de regiones ecológicas. El problema de este método es que da como resultado no exactamente "regiones indígenas", sino más bien la inserción de la población indígena en regiones que definitivamente son indígenas, sino mestizas. El método es claramente un avance en comparación con el antiguo enfoque de estudiar a la población indígena como si existiera sin relación con el mundo "exterior".

Todo esto nos tiene que servir de preámbulo para acercarnos a la problemática de la región indígena. ¿De qué manera podemos iniciar la construcción de un concepto teórico de región indígena?

\section{La antropología geográfica: La perspectiva macro}

A nivel macro destacan dos temas en la antropología mexicana: la discusión del área cultural de Mesoamérica y la discusión del impacto de la irrigación en la misma región mesoamericana.

La clásica definición de Mesoamérica se debe al etnólogo Paul Kirchhof, quien desde 1940 había formulado el concepto, ${ }^{8}$ pero existe una prehistoria, y la discusión fue iniciada por Jorge Vivó y Paul Kirchof en los años 1930, entrelazándose con un planteamiento hecho por Alfred Kroeber al principio del mismo periodo. ${ }^{9}$ Como el primer intento (de mi conocimiento, por lo menos) de formular un marco para el estudio de la distribución espacial de la población indígena, Kroeber cita como antecedente al Handbook of the American Indians North of Mexico, que contiene una lista de "doce entornos étnicos" (Mason, 1907). ${ }^{10}$

G. Holmes elaboró unos años más tarde el esquema de Mason, proporcionándole así a Wissler un fundamento para su posterior presentación de los indígenas norteamericanos en

8 Paul Kirchhof nació en Alemania en 1900, pero en 1928 dejó su país natal y desde 1936 residía y trabajaba en México, donde murió en 1972. Una muy buena biografía de Paul Kirchhof se encuentra en García Mora, 1987.

9 David Robichaux señala (en su Tesis Doctoral de la Universidad de Sorbona acerca de "la familia mesoamericana", sin fecha y sin paginación) que "hoy en día, parecería que este concepto original, que consideraba el área mesoamericana como un todo cultural cuya cohesión se remontaba a la época prehispánica, fuera cada vez más olvidado por los etnólogos", lo que no me parece ser el caso.

10 Con su acostumbrada amabilidad señala Harris que "al parecer, Kroeber ignoraba que Mason había empleado realmente el término "área cultural" en un artículo publicado en el Annual Report of the Smithsonian Institution en 1895" (Harris, 1979: 323; pobre ignorante, Kroeber, quiero decir), donde identifica "dieciocho entornos o áreas culturales" (Mason 1895: 646), y que en 1899 había modificado su esquema (Mason, 1899). 
su distribución espacial. En Los Indios de los Estados Unidos de América, que fue escrito alrededor de 1917 pero no se publicó hasta 1939, Clark Wissler plantea "he agrupado las diferentes tribus según las familias lingüísticas, puesto que, en mi opinión, ése era el modo más simple de clasificación a la vez que el más fácilmente comprensible para el lector no especializado. Es un hecho curioso que las tribus de esas diversas familias lingüísticas tienden a ser vecinas y constituyan de esta manera bloques geográficos. Frecuentemente el núcleo principal de una familia lingüística ocupa una zona geográfica y sólo presenta algunas ramas dispersas y aisladas. Por esta razón el agrupamiento de las tribus sobre la base de la lengua permite clasificarlas también de acuerdo con la geografía. Tenemos la esperanza de que este procedimiento brinde al lector una visión general del indio durante el periodo de la frontera en la historia de Estados Unidos" (Wissler, 1970: 9). ${ }^{11}$ Entre la redacción y la publicación había Wissler ya formulado un esquema de todas las culturas del mundo mediante nueve categorías (Wissler, 1923). ${ }^{12}$ Los trabajos de Otis Mason, G. Holmes y Clark Wissler eran pioneros, y en eso estriba su valor: son guías indispensables para el estudio y la descripción de los grupos étnicos en su distribución espacial, y para llevar a cabo un trabajo de catalogación. Pero más allá de este mérito padecen dos deficiencias. En primer lugar, una vez hechas las observaciones para un estudio más profundo de los grupos étnicos en cuestión, tienden a convertirse en una especie de camisas de fuerza, y se hace imposible o muy difícil siquiera hacer observaciones para cuestionar su verdad y proponer otra alternativa. En segundo lugar, se limitan a una enumeración de "rasgos", que luego se suman para establecer de manera mecánica, más allá de una extrapolación del "presente etnográfico", hacia atrás (y también, en cuanto sirvan para fines de planeación, también hacia adelante) no dicen nada acerca del proceso histórico (para combinar estos dos términos que son para Kroeber absolutamente incombinables).

El concepto de Mesoamérica, como lo formuló Kirchhof, pretende sustituir un número de confusas "clasificaciones geográficas de las culturas indígenas de América", entre las cuales "se distinguen fácilmente dos tipos", de los cuales "en el primero, se acepta una $\mathrm{u}$ otra de las divisiones corrientes del continente, basadas en la geografía política o en la biogeografía" (p. 28), mientras que "el segundo tipo de clasificación geográfica agrupa las culturas indígenas americanas en cinco grandes zonas: 1) Los recolectores, cazadores y pescadores de Norteamérica, 2) Los cultivadores inferiores de Norteamérica, 3) Los cultivadores superiores ("altas culturas"), 4) Los cultivadores inferiores de Sudamérica, y 5) Los recolectores y cazadores de Sudamérica" (p. 30).

De estas dos opciones, que corresponden respectivamente a la orientación historicista de Kroeber (1939) y al neoevolucionismo de Steward (1979: 78-97), Kirchhof se afilia a la primera, declarando acerca de los datos que presenta que "todo esto demuestra la realidad de Mesoamérica como una región cuyos habitantes, tanto los inmigrantes muy antiguos como los relativamente recientes, se vieron unidos por una historia común que los enfrentó como un conjunto a otras tribus del continente, quedando sus movimientos migratorios confinados por regla general dentro de sus límites geográficos, una vez entrados en la

11 Con este planteamiento coloca Wissler la identidad de las entidades que pretende estudiar en el dominio de la lengua, su duración en el tiempo deja un tanto en suspenso, haciendo una escueta referencia al "periodo de la frontera en la historia de Estados Unidos", y su extensión en el espacio se define como la extensión de agrupaciones que comparten la misma lengua, de manera que "el agrupamiento de las tribus sobre la base de la lengua permite clasificarlas también de acuerdo con la geografía”.

12 Un esquema que evidentemente no puede competir con el gigantesco aparato que construyó George Peter Murdock en Yale para el "Human Relations Area File", con 55 variables principales y 557 secundarias (Murdock, 1963). 
órbita de Mesoamérica" (p. 30).

"El término de Mesoamérica no es sinónimo de América Central, que excluye a México, pero se extiende hasta Panamá; ni de Middle America, término geográfico más técnico que abarca a México y Centroamérica. Mesoamérica designa un área que no es ni una región geográfica ni una unidad política, sino más bien un área cultural definida con base en las características comunes que se presentaron durante los tiempos anteriores a la Conquista" (Suárez, 1995: 35), y agrega que "a pesar de que la Conquista produjo cambios, que en más de un sentido modificaron el área, hubo cierta continuidad cultural como resultado de la supervivencia de muchos grupos indígenas que habían estado bajo la influencia de una nueva, y única, tradición cultural. desde este punto de vista lingüístico, el área era bastante bien definida en el sentido de que la mayoría de las familias que se encuentran en ella no se extienden más allá de sus límites" (ibídem).

En 1952 Julian Steward presentó su propuesta para la formulación de áreas culturales o, más bien, para acabar con ellas. "Ya que se supone que estas áreas han adquirido sus rasgos compartidos por medio de difusión sus límites son definidos por la mayor similitud de las sociedades a un centro que a otro centro diferente. Eso implica que la difusión se ha estado llevando a cabo durante un largo periodo de tiempo, lo que nos lleva al problema de la profundidad histórica en relación a la taxonomía" (Steward, 1952: 82). "Hasta donde el área cultural es percibida en términos de contenido, por lo general se supone que el centro de creatividad se mantenga dentro del área, que tenga sus raíces en una considerable antigüedad, y que les haya proporcionado rasgos a las sociedades dentro del área en todo momento" (Steward, 1952: 83).

"El concepto de área cultural se ha vuelto una herramienta tan importante en las operaciones de los antropólogos que al cuestionarla pareceríamos sembrar dudas acerca de la antropología misma”, declara Steward (1979: 79), después de hacer a un lado el concepto de Kulturkreis de los difusionistas (principalmente alemanes) y constatar que las influencias británicas de Malinowski y Radcliffe-Brown "aunque provocadores de nuevas ideas, no han llevado a clasificación sistemática alguna".

El desarrollo más pleno de los planteamientos de Julian Steward y seguidores en la discusión de Mesoamérica es el libro "Mesoamerica" (Sanders \& Price, 1968), donde los autores plantean la existencia de unidad y diversidad en Mesoamérica: "El área es de una enorme variedad geográfica. En el momento de la conquista era ocupada por un gran número de grupos lingüísticos y étnicos y mostraba un notable regionalismo en lo referente a características culturales; sin embargo, a pesar de esta diversidad, todos estos grupos componentes participaban en una sola gran tradición. Considerado estrictamente sincrónico, tal fenómeno constituye un área cultural. Diacrónicamente utilizaremos el término co-tradición" (Sanders \& Price, 1968: 6-7). ${ }^{13}$ La definición de un área cultural de Sanders \& Price se basa tanto en las características de las culturas involucradas como en las características geográficas de la región, en lo que siguen a Kroeber (1947), pero acerca de la relación entre las características culturales y las geográficas "sienten que rige una relación claramente causal" (Sanders \& Price, 1968: 7).

La discusión del impacto de la irrigación incluye aspectos de agronomía también y el papel de Eric Wolf y Angel Palerm ha sido de primera importancia.

En la discusión acerca de Mesoamérica, su extensión en el tiempo y el espacio y

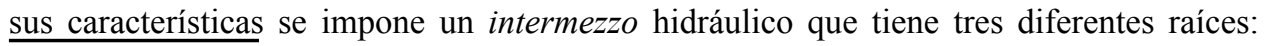

13 El concepto de co-tradición fue definido por Wendell C. Bennett, en base a sus trabajos en los Andes, como una delimitación regional donde "solamente se considera aquel territorio dentro del cual las culturas participantes formaron una área cultural durante cualquier periodo, y no el territorio de máxima expansión durante un periodo particular" (Bennett, 1948: 1); véase también Armillas, 1948. 
primero las especulaciones de Carlos Marx acerca de la posibilidad de que la comunidad/ sociedad asiática tuviera sus orígenes lógicas e históricas en la disponibilidad del agua y la posibilidad/necesidad de organizar la administración de esta misma agua (si se la quisiera aprovechar); segundo, la obra del "renegado" Karl Wittfogel y su tesis acerca del despotismo asiático; y tercero, las ideas de Angel Palerm acerca del origen específicamente hidráulico de la civilización mesoamericana.

Del trabajo de Marx surge una idea del modo de producción asiático que, con algunas reservas, se puede resumir así: "es un sistema en el cual aparece un poder estatal muy fuerte -político y económico- que se basa en la explotación generalizada de las comunidades aldeanas comprendidas en el territorio dominado por el Estado, explotación que se realiza por medio de la extracción de excedentes de la producción aldeana a través del tributo en especie o en trabajo (raras veces en moneda)" (Bartra, 1974: 15).

La controversia alrededor de la posible raíz de la sociedad asiática en factores hidráulicos empezó con dos breves artículos de Carlos Marx en The New York Daily Tribune en el verano de 1853: "British Rule in India" ("El gobierno británico en la India", Marx, 1853A) y "The Future of British Rule in India" ("El futuro del gobierno británico en la India", Marx, 1853B) retomando, sin embargo, algunos planteamientos anteriores hechos al respecto por Engels.

En estos dos breves artículos resume Marx lo que es en su opinión el carácter de la comunidad oriental: "Estas dos circunstancias - de una parte, el que los habitantes de la India, al igual que todos los pueblos orientales, dejasen en manos del gobierno central el cuidado de las grandes obras públicas, condición básica de su agricultura y de su comercio, y de otro, el de los hindúes, diseminados por todo el territorio del país, se concentrasen a la vez en pequeños centros en virtud de la unión patriarcal entre la agricultura y la artesanía- originaron desde tiempos muy remotos un sistema social de características muy particulares: el llamado village system. Este sistema era el que daba a cada una de estas pequeñas agrupaciones su organización autónoma y su vida particular" (Marx, 1853A: 356), y "Esas idílicas comunidades rurales, por inofensivas que pareciesen, constituyeron siempre una sólida base para el despotismo oriental; que restringieron el intelecto humano a los límites más estrechos, convirtiéndolo en un instrumento sumiso de la superstición, sometiéndolo a la esclavitud de reglas tradicionales y privándolo de toda grandeza y de toda iniciativa histórica. No debemos olvidar el bárbaro egoismo que, concentrado en un mismo pedazo de tierra, contemplaba tranquilamente la ruina de imperios enteros, la perpetuación de crueldades indecibles, el aniquilamiento de la población de grandes ciudades, sin prestar a todo esto más atención que a los fenómenos de la naturaleza, y convirtiéndose a su vez en presa fácil para cualquier agresor que se dignase fijar en él su atención. No debemos olvidar que esa vida sin dignidad, estática y vegetativa, que esa forma pasiva de existencia despertaba, de otra parte y por oposición, una fuerzas destructivas salvajes, ciegas y desenfrenadas, que convirtieron al asesinato en un rito religioso del Industán. No debemos olvidar que esas pequeñas comunidades estaban contaminadas por las diferencias de casta y por la esclavitud, que sometían al hombre a las circunstancias exteriores en lugar de hacerlo soberano de dichas circunstancias, que convirtieron su estado social que se desarrollaba por sí sólo en un destino natural e inmutable, creando así un culto grosero a la naturaleza, cuya degradación salta a la vista en el hecho de que el hombre, el soberano de la naturaleza, cayese de rodillas, adorando al mono Hanumán y a la vaca Sabbala" (Marx, 1853A: 358). Hay que tener en mente que Marx tenía en aquel entonces sólo treinta años y era profeta del progreso. Décadas y experiencias (algunas de ellas amargas) más tarde 
presenta la sociedad asiática de una manera bastante más equilibrada en El Capital.

Mientras que el análisis de Marx presta máxima atención al elemento económico, en particular al trabajo concreto, Karl Wittfogel centra su análisis en el elemento político, complementándolo con la tecnología. En un trabajo posterior, donde trata "el enfoque hidráulico a la Mesoamérica prehispánica”, señala Wittfogel que ya en 1940 había llamado la atención al carácter hidráulico de Mesoamérica.

Como indica el título original del artículo más significativo de Angel Palerm acerca del modo de producción asiático aplicado al caso de mesoamérica - "Una defensa del modo de asiático de producción según Marx y Wittfogel” (Palerm, 1970)-él avala plenamente el enfoque hidráulico al problema de Mesoamérica y, como indica también el título, intenta conciliar al análisis de Marx con el de Wittfogel. Pero antes de abordar los argumentos de Palerm en favor del enfoque hidráulico, resulta interesante ver su descripción de la situación al inicio del pleito sobre el desarrollo de Mesoamérica en el momento de la llegada de la obra de Gordon Childe y los primeros rumores acerca de la posibilidad de un evolucionismo que sería unilineal, durante la revolución que significaba en México la década de 1940, y antes de la llegada de la teoría de Wittfogel, teniendo en mente el comentario de Wittfogel: "En la primavera de 1940 impartí una conferencia en una universidad importante en la parte oriental de los EE. UU., dirigida a un grupo de orientalistas. Mi audiencia, que incluía a dos antropólogos, me escucharon con interés. Pero cuando señalé a la antigua Mesoamérica como una variedad de una sociedad hidráulica "asiática" los antropólogos, que conocieron bien la historia del antiguo México, me miraron, primero incrédulos y luego con diversión escasamente simulada" (Wittfogel, 1972: 64).

Sin embargo, el mismo año, 1940, escribió Wittfogel acerca de la situación hidráulica de México que "no tiene ríos importantes. Sus lagos, aunque más grandes en 1519 que hoy, nunca eran más que centros acuáticos en valles individuales de dimensiones variables. Separados por cordilleras altas, fue imposible articular los lagos alrededor de la Ciudad de México con los de los centros económicos en el este y el sur por medio de canales. Pero en el norte, donde la planicie era menos accidentada, nunca se intentó construir un largo canal. Evidentemente, la subasta natural de agua, que no solo alcanzaba para el sistema regional de irrigación, fue absolutamente incapaz de llenar los canales a una escala nacional. Ningún Nilo natural conectaba los diferentes centros ecológicos de México y no fue posible construir un Nilo artificial en su lugar. En cierto sentido, la situación era parecida a la de Japón, excepto en un aspecto extremadamente significativo. Los valles de irrigación centrífuga de Japón no poseían núcleo de construcción hidráulica concentrada alguna, mientras que los centros lacustres convergentes de México exigían que sus agricultores sedentarios desarrollaran obras públicas extensas para la protección de sus campos igual que para su irrigación. No había necesidad de una gran burocracia gerencial en Japón, mientras que en la América Central el crecimiento de centros urbanos de dimensiones "orientales" fue estimulada por una necesidad aparentemente inherente. Esta necesidad es documentada por el crecimiento de un gran número de centros independientes. Estos centros mostraron muchas diferencias significativas, pero al mismo tiempo todas poseían rasgos claramente burocráticos y teocráticos" (Wittfogel, 1940: 115, 116).

Tengo la impresión que su promoción de una imagen hidráulica de México ante los orientalistas el mismo año, 1940, no puede haber sido muy entusiasta. En primer lugar, se dudaba mucho de la capacidad de la agricultura mesoamericana de sostener la superestructura necesaria para llegar al estatus de "sociedad hidráulica" y así hacer el paso de una "economía natural" a una "economía política", ya que "en la década de los cuarenta se estaba bajo la influencia del dictum de Kroeber, que de hecho reducía la agricultura prehispánica a un 
nivel de tecnología y de productividad muy semejante al que es característico en el siglo XX de los grupos indígenas marginados y desculturados" (Palerm, 1970: 171). En segundo lugar, se dudaba de la existencia de una estructura política estatal, debido a "la persistencia de la versión tribalista ("iroquesa") de la sociedad mexica, enunciada por Bandelier y sostenida por Morgan" (Palerm, 1970: 171). Y en tercer lugar, se dudaba de la existencia de ciudades, limitando (o extendiendo, como se quiera) el papel de las concentraciones de población a un papel de "centros ceremoniales", "negando tácita o abiertamentemente carácter urbano a lugares como Teotihuacan y aún como Tenochtitlán" (Palerm, 1970: 171), muy al estilo del pensamiento general de Evon Z. Vogt, por ejemplo.

Ya en tiempos de Angel Palerm, hace hoy unos treinta años en lo que se refiere a la discusión hidráulica, los tres puntos fueron efectivamente rebatidos. Recorriendo la bibliografía en una "visión personal de la evolución que ha tenido, dentro de la antropología mexicana la investigación de problemas relacionados con agricultura" (González, 1988: 55) se encuentra vestigio tras vestigio de descubrimientos que rebaten la postulada incapacidad agrícola para sostener la construcción de centros ceremoniales y ciudades, más toda la superestructura política y de especialistas de todo tipo. La idea de la existencia de una organización política solamente rudimentaria ha sido sólidamente refutada también, a través del estudio de la formación del estado en Mesoamérica. Hablando del caso de Teotihuacan, y el enfoque hidráulico, advierte Barbara Price que "un número de cuestiones epistemológicas serias se presentan en el momento de querer extender una proposición teórica más allá del dominio para el cual fue originalmente formulada" (Price, 1986: 169).

Con lo que se podía proceder a experimentar con la aplicación del enfoque hidráulico a Mesoamérica, volviendo a Palerm. Una temprana formulación de la sociedad hidráulica de Palerm muestra claramente, como nos lo indica Andrés Fábregas, la influencia de los planteamientos de Wittfogel: "El despotismo surge en las sociedades de tipo oriental como un resultado de diversos rasgos institucionalizados que se entrelazan y sostienen mutuamente. Entre estos rasgos son de especial importancia: las realizaciones del Estado en construcciones, en organización y en apropiación; el éxito del Estado en mantener muy débil el sistema de propiedad privada y en ligar a sí la religión dominante; el tipo específico de la clase dominante: una burocracia monopolista. En las civilizaciones de tipo oriental, el Estado tiende a ocupar todo el ámbito de la sociedad, a intervenir, dirigir y controlar todas las actividades sociales. En los planos superiores de la sociedad oriental los jefes militares y los sacerdotes son funcionarios del gobierno; la propiedad de la tierra, así como la de las obras hidráulica, es estatal; el comercio está controlado por el gobierno al igual que la producción manufacturera; la clase dominante aparece constituida por una numerosísima y potente burocracia administrativa que va tomando carácter hereditario" (Palerm, 1957: 24). Comparando esta declaración con su tesis de unos tres años antes, dedicada a "El regadío en Mesoamérica y la revolución urbana" (Palerm, 1953), se ve claramente un cambio de interés hacia la esfera política y el aparato gubernamental en la sociedad hidráulica.

También otro especialista en la etnohistoria mesoamericana acepta la idea de una sociedad asiática: "la identificación de los distintos modos de producción precapitalistas requieren todavía mucha elaboración, pero creo, sin embargo, que la economía del México antiguo se puede describir como una variedad de lo que se ha llamado modo de producción asiático. Considero como criterio clave que la producción estaba organizada en base al control político de la tierra y del trabajo y que la clase dominante coincidía con el personal gobernante y recibía sus ingresos en forma de tributo" (Carrasco, 1978: 66). Karl Wittfogel 
sugiere que "hoy es ya costumbre hablar de la sociedad hidráulica (oriental) poseyendo por lo menos tres particularidades mayores: a) el ambiente ecológico, b) las actividades agro-gerenciales inspiradas por este ambiente, y c) el surgimiento de un estado despótico" (Wittfogel, 1972: 62), y podemos hacer el experimento de armar un modelo "hidráulico" de Mesoamérica, tomando en cuenta las anteriores observaciones.

En términos generales, el argumento socio-político de Doolittle es negativo y va dirigido contra la interpretación despótica de Wittfogel. Doolittle se opone a la idea de que la formación del estado despótico fuera una precondición para el desarrollo de las construcciones de irrigación: "la irrigación por medio de canales, como se conoce ahora, fue desarrollada mucho antes del periodo en el cual el pueblo prehistórico de México alcanzara un nivel suficientemente sofisticado de organización política, económica, y artística como para ser considerado un estado" (Doolittle, 1990: 146). Con este planteamiento coloca Wissler la identidad de las entidades que pretende estudiar en el dominio de la lengua, su duración en el tiempo deja un tanto en suspenso, haciendo una escueta referencia al "periodo de la frontera en la historia de Estados Unidos", y su extensión en el espacio se define como la extensión de agrupaciones que comparten la misma lengua, de manera que "el agrupamiento de las tribus sobre la base de la lengua permite clasificarlas también de acuerdo con la geografía". Inmediatamente parece que eso apoya a los que postulan que el control del agua en general, y más particularmente la irrigación, no solamente precedía sino causaba la formación del estado (haciendo referencia a Wittfogel, 1957, y admitiendo que la cuestión es mucho más compleja, citando a Price, 1971). Virtualmente todos los argumentos que cubren miles de hectáreas (Adams, 1968: 370-371; R. C. Hunt, 1988), y pocas de las redes de canales de irrigación conocidos en México satisfacen esta condición.

Acerca de los sistemas en México señala que "no eran del mismo orden como aquellos del Valle de Huang Ho, por ejemplo, y eran pequeños y elementales en términos de sus implicaciones sociopolíticas" (Doolittle, 1990: 146). Otros investigadores opinan que "las consideraciones de los detalles de los sistemas de campo y una evaluación del trabajo actual proporciona la base para considerar estos patrones de campo como el resultado esperable de un esfuerzo moderado y no como un logro fantástico del tiempo de los gigantes", y que "sería erróneo imaginar la existencia de evidencia de un sistema sofisticado y amplio de manejo del agua. Cada sistema de campos no es solamente una unidad pequeña y autónoma, sino probablemente la obra de un agricultor solitario o un grupo de familias" (Woodbury \& Neely, 1972: 125). Doolittle documenta, por medio de la siguiente tabulación, las dimensiones modestas de los sistemas de irrigación que han sido discutidos en su libro.

Es cierto, como lo planteó Eric Wolf, que México para su desarrollo y producción agrícola había dependido de la irrigación: "La irrigación ha sido también importante en Mesoamérica, por todas partes pequeños diques y canales sirven para almacenar agua y canalizarla hasta las tierras que la necesitan, protegiendo así la `primera cosecha de las amenazas de la sequía y ayudando a la segunda cosecha a crecer en un suelo que de otra manera permanecería estéril" (p. 23 en la edición en epañol de Sons of the Shaking Earth). Pero la anterior tabla confirma también lo planteado por Teresa Rojas, que existen numerosas localidades aptas para la irrigación, pero ninguna con suficiente agua de superficie como para construir sistemas de gran escala (Rojas, 1985: 192), el único caso es probablemente el de Cuautitlán, donde el agua es llevada de un valle al siguiente. Eso evidentemente lo hace difícil mantener el argumento del estado mesoamericano como producto de sistemas de irrigación de gran escala pero, de acuerdo a Doolittle, no apoya el argumento contrario (sostenido por Kappel, 1974: 163) que solamente donde hay estados de un alto grado de 
organización pueden surgir sistemas de irrigación.

\section{La antropología y la geografía: Presente, futuro y perspectivas}

Antes de formular una conclusión a lo anterior que admitidamente representa un abanico muy amplio de casos antropológicos, será preciso señalar que, exactamente debido a la enorme amplitud que cubre el terreno combinado cubierto por la antropología y la geografía.

Como conclusión de esta presentación de los terrenos compartidos por la antropología y la geografía, me parece que sería justo y relevante. Depende, sin embargo, de la definición de antropología endosada.

De entre todas las muy diferentes y en muchos casos incompatibles concepciones de la naturaleza de la antropología, aparte de ser una disciplina que se dedica a la investigación partiendo del concepto central de "cultura", se repiten tres rasgos que vienen a constituir el denominador común de la antropología en sus diversas versiones: es una disciplina que consigue su información por medio de trabajo de campo, que mantiene una ambición holista y que trata sistemáticamente la alteridad.

\section{Bibliografía}

ADAMS, Robert McC.

1968 "Early civilizations, subsistence, and environment", en Yehudi A. Cohen (edit.). Man in adaptation. The biosocial background. Chicago: Aldine, pp. 363-377.

ARMILLAS, Pedro

1948 “A sequence of cultural development in Mesoamerica", en W. C. Bennett (edit.). A Reappraisal of Peruvian Archaeology, Menasha, Memoirs of the Society for Archaeology, 1948: 105-111.

BARTRA, Roger

1974 "Prólogo", en Bartra, Roger (comp.). El modo de producción asiático. México: ERA, pp. 11- 47.

BASSOLS BATALLA, Ángel

1979 México. Formación de regiones económicas. México: Universidad Nacional Autónoma de México.

BENNETT, Wendell C. (edit.)

1948 "The Peruvian Co-tradition”, American Antiquity, vol. 13.

BOAS, Franz

1887 "The study of Geography”, en Franz Boas (1966). Race, Language, and Culture. New York: The Free Press, pp. 639-647.

1966 Kwakiutl Ethnography. Chicago: University of Chicago Press.

BOURDIEU, Pierre

1970 "La casa o el mundo invertido", en Pierre Bourdieu (1991). El sentido práctico, Madrid: Taurus, pp. 419-437.

BRAUDEL, Ferdinand

1984 Civilización material, economía y capitalismo, siglos XV-XVII. Madrid: Alianza.

1992 El Mediterráneo y el mundo mediterráneo en la época de Felipe II, I-II. México: Fondo de Cultura Económica.

BRIGGS, Asa

1989 “Qué es la historia de la cultura popular?”, en la Revista Historias N. ${ }^{\circ}$ 23, Octubre 1989-Marzo 2000: 3-12.

BROWN, Denise Fay

1999 "El paisaje cultural y los mayas yuacatecos", en Quivera, Año 1, N. ${ }^{\circ}$ 1: 75-85. 
BURKE, Peter

1999 La revolución historiográfica francesa. La Escuela de los Annales: 1929-1989, Barcelona, Gedisa.

CARMAGNANI, Marcello

1988 El regreso de los dioses. El proceso de reconstitución de la identidad étnica en Oaxaca. Siglos XVII y XVIII. México: Fondo de Cultura Económica.

CARRASCO, Pedro

1978 "La economía del México prehispánico", en Pedro Carrasco \& Johanna Broda (eds.) (1978). Economía política e ideología en el México prehispánico. México: Nueva Imagen, 15-74.

CHEVALIER, Jaques

1958 Historia del pensamiento. Madrid: Aguilar.

CLAVAL, Paul

1974 Evolución de la geografía humana. Barcelona: Oikos-Tau.

1982 Espacio y poder. México: Fondo de Cultura Económica.

COLIN, A.

1971 Les régions britanniques. París.

CORTEZ, Claude,

1991 (comp). Geografia histórica. México: Instituto Mora.

COUTAU-BÉGARIE, H.

1983 Le phenomène nouvelle histoire. París.

CROMBIE, A. C.

1989 Historia de la ciencia: De Agustín a Galileo, tomos I, II. Madrid: Alianza.

CUNNINGHAM, Clark E.

1964 "Order in the Atoni Haouse", en Lessa \& Vogt (eds.) Reader in Comparative Religion. An Anthropological Approach. New York, Harper \& Row, 1972: 116135.

DARNTON, Robert

1987 La gran matanza de gatos y otros episodios en la historia de la cultura francesa. México: Fondo de Cultura Económica.

DOOLITTLE, William E.

1990 Canal Irrigation in Prehistoric Mexico. The Sequence of Technological Change. Austin: University of Texas Press.

FEBVRE, Lucien

1922 La tierra y la evolución humana. Introducción geográfica a la historia. México: UTEHA, 1955 (org. 1922).

1942 Le problème de l'incroyance au XVI siècle. La religion de Rabelais. París.

1944 Amour sacré, amour profane. Autour de l'Heptaméron. París: Folio.

1956 Lutero, un destino. México: Fondo de Cultura Económica.

1970 "La tarea actual: Métodos biológicos, métodos geográficos", en Claude Cortez, (comp.) (1991). Geografía histórica. México: Instituto Mora, pp. 25-34.

1985 Erasmo, la contrarreforma y el espíritu moderno. Barcelona: Orbis.

1993 Combates por la historia. Barcelona: Ariel.

GARCÍA MORA, Carlos

1987 “Paul Kirchhoff”, en Lina Odema Güemes \& Carlos García Mora (Coord.) (1987). La antropología en México. Panorama histórico. México, INAH, tomo 10: 352-360.

GEERTZ, Clifford

1994 Conocimiento local. Ensayos sobre la interpretación de las culturas. Barcelona:Paidós. 
1987 La interpretación de las culturas. Barcelona: Gedisa.

GONZÁLEZ JÁCOME, Alba

1988 "La agricultura mesoamericana", en Carlos García Mora \& Martín Villalobos Salgado (Coords.) (1988). La antropología en México. Panorama histórico, tomo 4: "Las cuestiones medulares (etnología y antropología social". México: INAH, pp. 55-190.

GOSSEN, Gary

1972 "Temporal and Spatial Equivalents in Chamula Ritual Symbolism", en Lessa \& Vogt (eds.) (1972). Reader in Comparative Religion. An Anthropological Approach. New York: Harper \& Row, pp. 138-149.

GRIJALBO

1995 Enciclopedia de Grijalbo. México: Grijalbo.

HALL, E. T.

1989 La dimensión oculta. México: Siglo XXI.

1990 El lenguaje silencioso. México: CNCA.

HARRIS, Marvin

1979 Desarrollo de la teoría antropológica. México: Siglo XXI.

HARTSHORNE, Richard

1967 “Geografía. I: Objeto", en Enciclopedia Internacional de las Ciencias Sociales, Vol. 4. Madrid: Aguilar, 1967, pp. 110-111.

HOBSBAWM, Eric

1979 “Historia económica y social”, en Paul Barker (ed.) (1979). Las ciencias sociales de hoy, México: Fondo de Cultura Económica, pp. 112-122.

HOFFMAN, Odile \& Fernando I. Salmerón Castro (coords.)

1997 Nueve estudios sobre el espacio. Representación y formas de apropiación. México: CIESAS/ORSTOM.

HOLMES, G.

1914 "Areas of American Culture Characterization, tentatively outlined as an aid in the study of antiquities". American Anthropologist vol. 16: 413-416.

HUGHES, H. S.

1969 The Obstructed Path. New York.

HUMBOLDT, Alejandro von

1930 Ensayo político sobre la isla de Cuba, I-II. La Habana: Cultura S. A.

1991 Ensayo político sobre el Reino de la Nueva España. México: Porrúa.

HUNT, Robert C.

1988 "Size and Structure of Authority in Canal Irrigation Systems", Journal of Anthropological Research vol. 44: 335-355.

KAPPEL, Wayne

1974 "Irrigation Development and Population Pressure", en Theodore E. Downing \& McGuire Gibson, (eds.) (1974). Irrigation's Impact on Society. Tucson: University of Arizona Press, pp. 159-167.

KIRCHHOFF, Paul

1967 “Mesoamérica”, en Jorge A. Vivó et al. (1992). Una definición de Mesoamérica. México: Universidad Nacional Autónoma de México, pp. 28-45.

KJELLÉN, Rudolf

1924 Der Staat als Lebensform. Berlín, Vowinkel (org. 1916).

KORSBAEK, Leif

1997 "Franz Boas, su novia y la antropología cultural”, en Ciencia Ergo Sum vol. 4, N. 
2: $180-182$.

2000 "La historia de las mentalidades y la antropología en la actualidad", Ciencia Ergo Sum, Vol. 7, No. 2: 189-199.

KROEBER, Alfred L.

1917 "The Superorganic", en American Anthropologist vol. 19: 163-213.

1925 Handbook of the Indians of California. Washington: Bureau of American Ethnology, Smithsonian Institution.

1935 "Science and History in Anthropology", en American Anthropologist vol. 37: 539-569.

1939 "Cultural and Natural Areas of Native North America”, en American Archeology and Ethnology vol. 38. Berkeley, University of California Publications.

LE ROY LADURIE, E.

1988 "Un concepto: La unificación microbiana del mundo (Siglos XIV al XVII)", Historia N. $^{\circ}$ 21: 33-69.

LÉVI-STRAUSS, Claude

1973 Anthropologie Structurale II, París, Plon.

MALINOWSKI, Bronislaw

1973 Los argonautas del Pacífico Occidental. Barcelona: Península.

MARCO POLO

1984 El libro de Marco Polo. Madrid: Alianza.

MARX, Carlos

1853a El gobierno británico en la India.

1853b El futuro del gobierno británico en la India

MASON

1895 "Influence of Environment upon human industries or arts", Annual Report of the Smithsonian Institution, p. 137-161.

1899 “Aboriginal American Zootechny”, American Anthropologist vol. 1: 45-81.

1907 "Environment". Handbook of American Indians North of Mexico, Part I, Washington Bureau of American Ethnology, vol. 30: 427-430.

MEINIG, Donald

1976 "The beholding eye: ten versions of the same scene", Landscape Architecture 66: 47-54.

MIER, Raymundo

1996 "Espacio y violencia ritual", en Cuicuilco vol. 2, N. ${ }^{\circ}$ 6: 121-134.

MIKESELL, Marvin W.

1969 "Ratzel, Friedrich”, en David L. Sills, dir. (1967). Encliclopedia Internacional de las Ciencias Sociales, vol. 9: 95-96. Madrid: Aguilar.

MINGUET, Charles

1985 Alejandro de Humboldt. Historiador y geógrafo de la América española (17991804). México: Universidad Nacional Autónoma de México.

MORENO, D.

1975 Clásicos de la ciencia política. México: Universidad Nacional Autónoma de México.

MURDOCK, George Peter

1963 Outline of World Cultures. New Haven, Human Relations Area Files.

NISBET, Robert

1969 La formación del pensamiento sociológico, tomos I y II. Buenos Aires: Amorrortu.

ORTEGA Y MEDINA, Juan A.

1965 "Estudio preliminar", en Alejandro von Humboldt (1991). Ensayo político sobre 
el Reino de la Nueva España. México: Porrúa, pp. vi-liii.

1965 "Estudio preliminar", en Alejandro von Humboldt (1991). Ensayo político sobre el Reino de la Nueva España. México: Porrúa, pp. vi-liii.

PALERM, Angel

1953 El regadio en Mesoamérica y la revolución urbana. Tesis de Licenciatura, ENAH.

1957 "Evolucionismo: unilineal, multilineal", en Palerm, 1992, pp. 9-33.

1970 "La teoría de la sociedad oriental aplicada: Mesoamérica", en Palerm, 1992, pp. 160-195.

1992 Agricultura y sociedad en Mesoamérica. México: Ed. Gernika.

PARSONS, Elsie Clews

1936 Mitla, Town of the Souls. Chicago: University of Chicago Press.

PLEWE, Ernst

1969 “Ritter, Karl”, en David L. Sills, (dir.). (1967). Encliclopedia Internacional de las Ciencias Sociales. Madrid: Aguilar, Vol. 9: 381-383.

POZAS ARCINIEGA, Ricardo

1987 Chamula. México: Instituto Nacional Indigenista.

PRICE, Barbara

1986 "Teotihuacan as World-System: Concerning the Applicability of Wallerstein's Model”, en Andrés Medina (ed.) (1986). Origen y formación del Estado en Mesoamérica. México: Instituto de Investigaciones Antropológicas / Universidad Nacional Autónoma de México, pp. 169-197.

RAISON, Jean-Pierre

1988 "Geografía histórica”, en Jaques Le Goff, Roger Chartier \& Jauqes Revel, (comps.) (1988). La nueva historia. Bilbao: Mensajero, pp. 234-246.

RATZEL, Friedrich

1889 Anthropogeographie (existe edición en español, traducido como "Las razas humanas"). Madrid: España.

RAULFF, U.

1988 “Der streitbare Prälat. Lucien Febvre”, en Lucien Febvre (1988). Das Gewissen des Historikers. Berlin: pp. 235-251.

ROJAS RABIEL, Teresa

1985 "La tecnología agrícola mesoamericana en el siglo XVI", en Teresa Rojas Rabiel \& William T. Sanders (eds.). Historia de la agricultura, época prehisp, siglo XVI, tomo 1. México: INAH, pp.129-214.

RUTSCH, Mechthild

1984 El relativismo cultural. México: Editorial Línea.

SANDERS, William T. \& PRICE, Barbara J.

1968 Mesoamerica. The Evolution of a Civilization. New York: Random House (Studies in Anthropology AS 9).

SCHAMA, Simon

1995 Landscape and memory. Toronto: Random House of Canada.

SELIGMAN, Carl G.

1910 The Melanesians of British New Guinea. Cambridge.

SEMPLE, Ellen Churchill

1911 Influences of geographic environment on the basis of Ratzel's system of 
anthropogeography. New York: Holt.

STEINMETZLER, Johannes

1956 "Die Anthropogeographie Friedrich Ratzels und ihre ideengeschichtlische Wurzeln", Bonner Geographische Abhandlungen, 19: 1-151.

STEWARD, Julian H.

1952 "Culture area and cultural type in Aboriginal America: Methodological considerations", en Julian H. Steward (1979). pp. 78-97.

1979 Theory of social change. The methodology of multilinear evolution (segunda edición, originalmente publicado en 1955). University of Illinois Press: Urbana.

SUÁREZ, Jorge A.

1995 Las lenguas indígenas mesoamericanas. México: INI/CIESAS.

TAX, Sol

1937 "The Municipios of the Midwestern Highlands of Guatemala". American Anthropologist, vol. 39, 1937: 423-444 (citado de la traducción al español: "Los municipios del Altiplano mesoccidental de Guatemala (1937)", en Leif Korsbaek, (comp.). Introducción al sistema de cargos, Toluca, UAEM, 1996: 87-112).

TYLOR, Edward Burnett

1861 Anahuac or Mexico and the Mexicans, Ancient and Modern. London: Longman, Green, Longman \& Roberts.

VANCE, Rupert B.

1976 "Región”, en David L. Sills (ed.) (1976). Enciclopedia Internacional de las Ciencias Sociales vol. 8. Madrid: Aguilar, pp. 161-164.

VARGAS MARTÍNEZ, Gustavo

1996 América en un mapa de 1489. México: Taller Abierto.

WARTOFSKY, Max

1986 Filosofía de la ciencia. Madrid: Alianza.

WISSLER, Clark

1923 Man and culture. New York: Thomas Y. Crowell.

1970 Los indios de los Estados Unidos. Buenos Aires: Paidós.

WITTFOGEL, Karl A.

1940 "The society of prehistoric China". Studies in Philosophy and Social Science vol. 8: 138-186. Institute of Social Research.

1957 Oriental despotism. New Haven: Yale University Press.

1972 "The Hydraulic Approach to Pre-Hispanic Mesoamerica", en F. Johnson (ed.) (1972). Chronology and Irrigation. Austin: University of Texas Press, pp. 59-80.

WOLF, Eric R.

1967 Pueblos y culturas de Mesoamérica. México: ERA.

WOODBURY, Richard B. \& Neely, James A.

1972 "Water Control Systems of the Tehuacan Valley", en Richard S. McNeish \& Fredrick Johnson (eds.) (1972). The prehistory of the Tehuacan valley. Chronology and irrigation", vol. 4. Austin, University of Texas Press, pp. 81-153. 